Article

\title{
Availability and Fade Margin Calculations for 5G Microwave and Millimeter-Wave Anyhaul Links
}

\begin{abstract}
Attila Hilt
Nokia Software, Cloud Core, Budapest Technology Center; H-1083, Bókay János utca 36-42, Budapest, Hungary; attila.hilt@nokia.com

Received: 26 October 2019; Accepted: 28 November 2019; Published: 2 December 2019

Abstract: The deployment of new radio access technologies always provides a good opportunity and timing to optimize the existing mobile front- and backhaul (commonly called "anyhaul"). The legacy systems (Long-Term Evolution (LTE), High-Speed Packet Access (HSPA), third-generation mobile $(3 G)$, second-generation mobile (2G)) already extensively utilize the transmission and transport capacities of the mobile anyhaul. With the current launch of $5 \mathrm{G}$ (fifth-generation mobile) and recent LTE-A (Advanced Long-Term Evolution), additional new transmission capacities are required again. Depending on the traffic and network topology, additional cell sites are built, and even more locations are connected with fiber optics. The existing microwave and millimeter-wave links are rotated toward those aggregation points that already have optical-fiber access. Due to the increased cell-site density, the average distance of the radio access links can be reduced by network and topology optimization. The reduced hop lengths combined with adaptive modulation and automatic power control bring an opportunity for capacity increase in shortened radio links. Links newly deployed for 5G find a wide spectrum in the millimetric $\mathrm{V}, \mathrm{E}, \mathrm{W}$, and $\mathrm{D}$ frequency bands. This paper discusses the availability and hop-length targets of the anyhaul links that should be carefully kept by proper planning and monitoring.
\end{abstract}

Keywords: 5G; mobile anyhaul; hop length; rainfall rate; system gain; availability; outage

\section{Introduction}

This invited paper is an extended version of the paper presented at the 42nd Telecommunications and Signal Processing conference [1]. The paper investigates the recommended hop length and availability of microwave and millimeter-wave $(\mu / \mathrm{mmW})$ radio links operating in traditional and new frequency bands. In Sections 2 and 3, it is shown that, in addition to the preferred fiber-optical access, $\mu / \mathrm{mmW}$ radio links continue to play an essential role in fronthaul and backhaul (commonly called "anyhaul") deployments of future mobile networks. In Section 4, a straightforward calculation method is given for the fade margin (FM) of the links by using radio equipment parameters and system gain (SG). Then, it is explained how to determine link availability from the calculated FM and for the given hop length by taking rain and atmospheric attenuation into account. In Section 5, maximum recommended hop-length curves are plotted as a function of rain-rate intensity for the different frequency bands. The paper-as a planning guideline-focuses on real deployment scenarios. Compared to earlier research and case studies, a general approach is presented for the practical link designs [1]. With the step-by-step calculation method presented, the different antenna size, the link polarization, and the used modulation modes can be taken into account. The presented calculation method and charts provide useful help in the planning phase of newly deployed $\mu / \mathrm{mmW}$ links. The results also help in optimization projects, when existing links are shortened by rotating toward new fiber access points. For the first time, maximum hop-lengthvs vs. rain-rate curves are plotted that belong to the pre-determined availability of the radio links. Earlier, these calculations 
were done using planning tools; here, the results are plotted by calculations of a simple Excel macro. The charts presented in Section 5 are illustrative examples, and the presented method can be used for any equipment and antenna combinations having different system and antenna gain values. Finally, in Section 6, an interesting conclusion is drawn; in Central/Eastern Europe, even smaller countries exhibit significant geographical variations of rainfall-rate intensities. Therefore, to maximize hop lengths for a given bit rate and SG, the local rainfall-rate statistics are recommended to be used during deployment and optimization. Finally, the calculation method is helpful in the monitoring phase of mobile anyhaul networks, when field results of the running $\mu / \mathrm{mmW}$ links are compared to the planned parameters.

The new radio access technologies (RATs) enable diverse services and different use cases in mobile networks (NWs). On one hand, the 5G (fifth-generation mobile) broadband services may require Gbps (Gigabit/second) peak data rates or even beyond. On the other hand, several critical services, e.g., remote control, robotics, or vehicular applications, require ultra-high reliability and low latency (Figure 1) [2]. Therefore, the deployment of 5G necessitates a quick expansion of the fiber-optical transport network, as well as the $\mu / \mathrm{mmW}$ radio links in the entire mobile front- and backhaul [1-6]. The existing mobile anyhaul networks already provide the transmission capacity for the recently deployed Long-Term Evolution (LTE-A (Advanced), LTE) evolved Node-Bs, as well as the capacity for the legacy second- and third-generation $(2 \mathrm{G} / 3 \mathrm{G})$ base stations in most of the countries $[7,8]$.

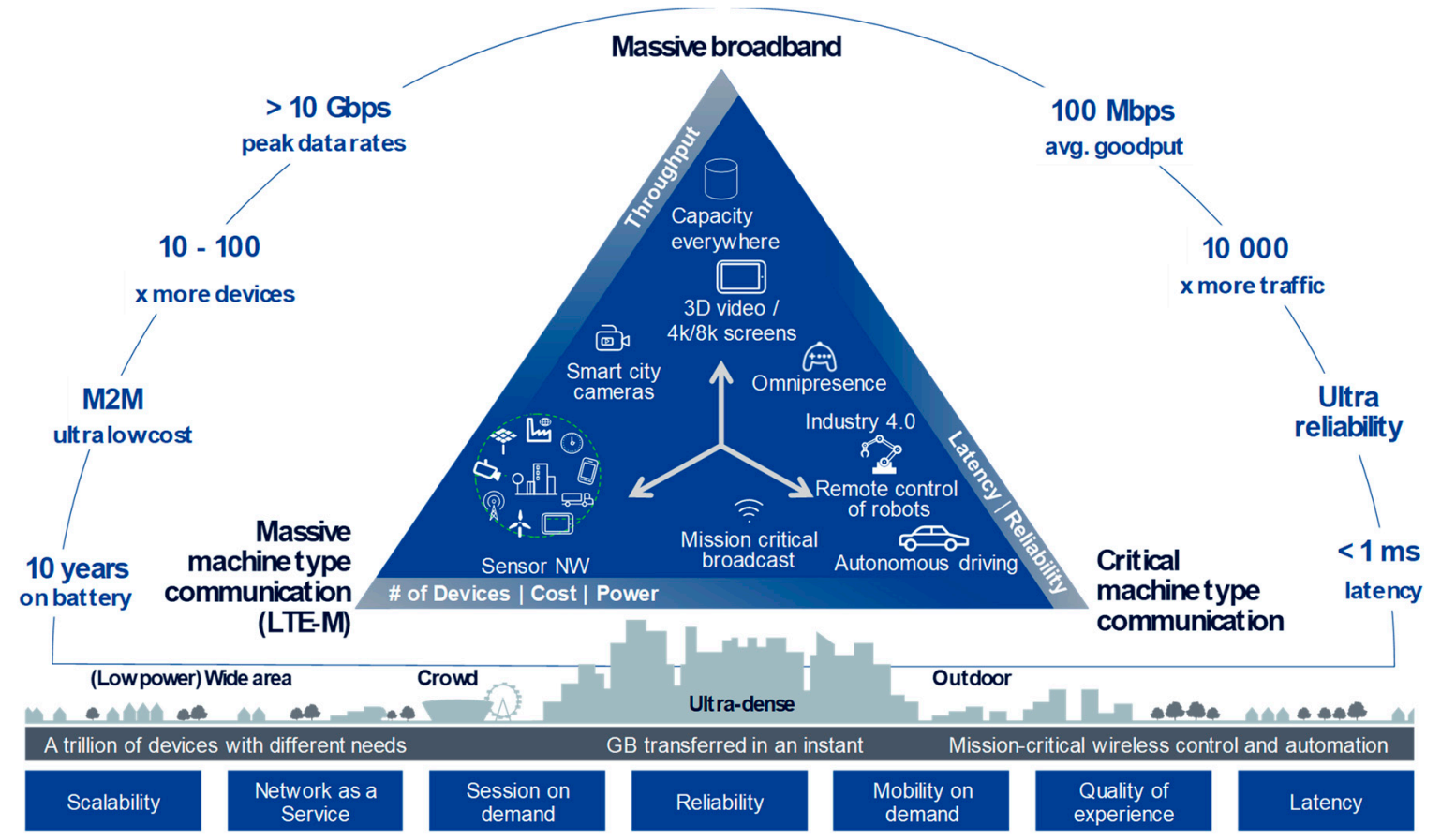

Figure 1. Fifth-generation mobile (5G): enabler for diverse use cases and services.

With the new 5G radio access points (RAPs), the density of sites is further increasing. Combined systems mesh various generations that are either legacy 2G sites, 3G Node-Bs, LTE eNode-Bs, or new 5G RAPs. The different RATs (or simply "generations") are frequently co-located to accelerate network rollouts, and they re-use earlier site investments to benefit from the capacity of the existing front- or backhaul. Earlier RATs are continuously modernized, often "re-farmed" toward 4G and 5G, resulting in a continuous expansion and optimization of the mobile anyhaul [1-9]. This paper investigates how the earlier deployed and new $\mu / \mathrm{mmW}$ links can contribute to the demands of bandwidth increase. Topology optimization, shortened radio links, adaptive modulation, and automatic transmit power control (ATPC) techniques can all contribute to extra capacity for the sites. However, for 5G, low latency and high availability requirements should also be fulfilled [2,5]. 


\section{Connection Options and Topology Optimization after Site Densification}

With the deployment of pico-cells and 5G introduction, the distance between neighboring sites is continuously decreasing. Meanwhile, the capacity demands of the sites are increasing. As a result, more and more locations require fiber-optical connection or microwave links with increased access transmission capacity [1-8]. The rapid network expansion inherently provides the possibility of optimization by means of topology re-planning. Thanks to the site densification, the hop lengths of the micro- and millimeter-wave access links can be reduced. A recent case study estimated significant hop-length reduction with 5G deployment [9]. The shorter links can either use higher millimeter-wave frequencies where available bandwidths are wider; alternatively, when the same hardware is re-used, the average output power can be regulated by ATPC, and elevated modulation can provide higher bit rates [9-14]. Thus, the access capacity can be increased and, with careful re-design, the possible radio interference can simultaneously be reduced. Figure 2 shows two connection scenarios: how $5 \mathrm{G}$ and LTE cells can be connected to the LTE and 5G cores in the early 5G deployment phase, and then to a common 5G core in the mature phase of 5G. More connection options are discussed in Reference [3].

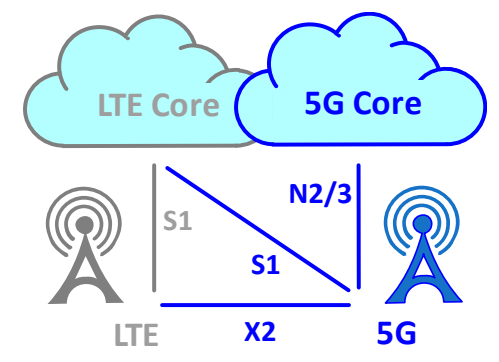

(a)

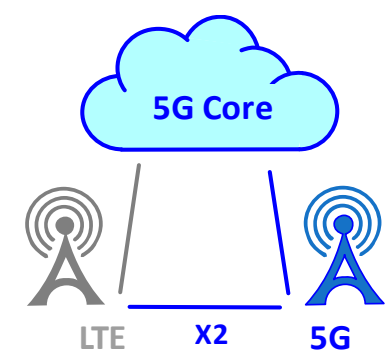

(b)

Figure 2. Different 5G interfaces: (a) in early 5G phase; (b) in mature 5G phase.

As an example, the $\mu / m m W$ links of an urban access network are shown (dark lines) in Figure 3, as seen in the link planning tool. Line-of-sight (LoS) information for possible new radio hops is plotted with light-green lines. High sites having fiber-optical access points are considered as transmission hubs (e.g., the locations 102A and 270C in Figure 3) and are target end-points of new links deployed after site densification.

Route diversity can be achieved with short radio chains composed of a few $\mu / \mathrm{mmW}$ hops and fiber-optical loop-back. Alternatively, the entire loop can be fiber-optic and, from the aggregation points, radio links can access the sites in star or in tree topology $[8,15]$. It should be mentioned also that very long radio chains of multiple hops increase the delay and, therefore, cannot be tolerated by low latency $5 \mathrm{G}$ services. Finally, a full mesh topology composed of $\mu / \mathrm{mmW}$ radios, free-space optical (FSO) links, and fiber-optical cables provides the mobile anyhaul [16-18]. Satellite links are very rarely used in Europe due to the high associated installation and lease costs and the relatively low capacity provided. Twisted pair or coaxial cables are limited in the bandwidth distance product; therefore, metallic cables were step-by-step replaced by optical fibers. Lightweight optical fibers are already widely used for remote antenna heads as feeder lines, and there is a significant research activity of radio-over-fiber (RoF) systems to deliver combined "fiber/wireless" networks for a reduced cost, with easier installation to support 5G deployments [5,17-23]. 


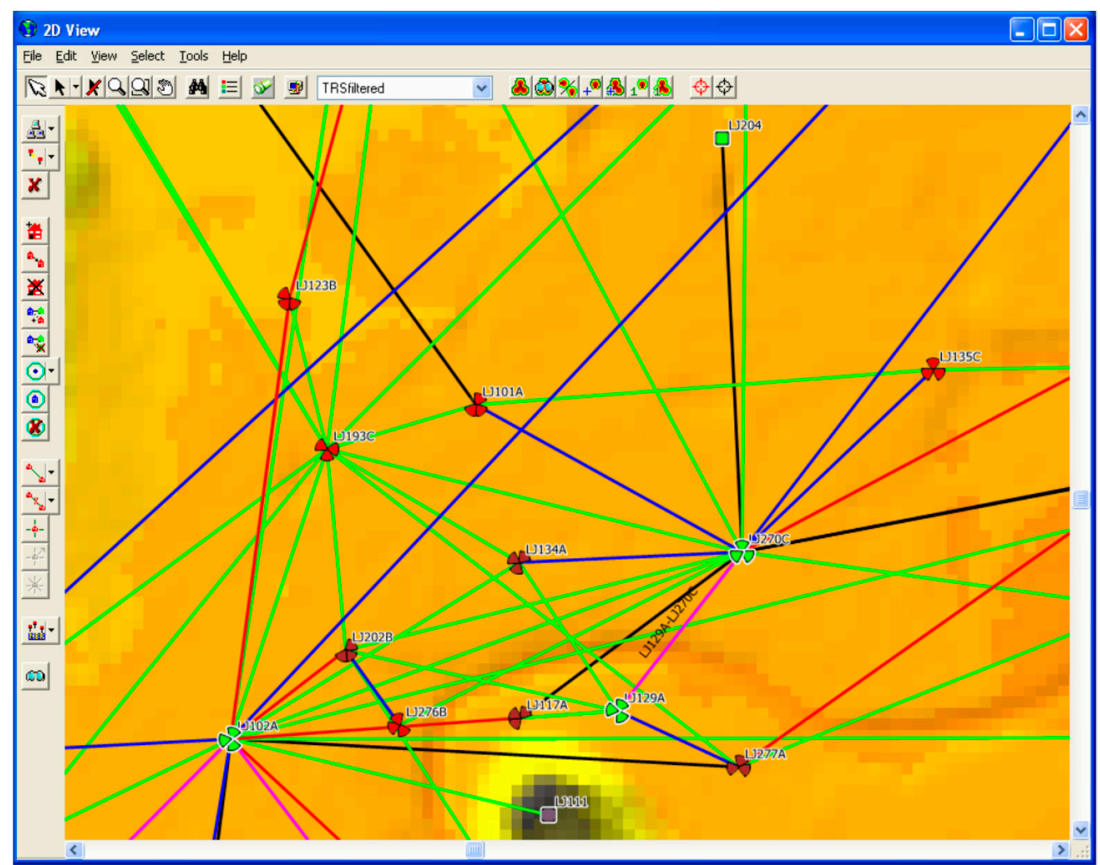

Figure 3. Example of topology re-planning for new and co-located sites.

The evolving networking scenario is shown in Figure 4. Due to low latency requirements, cloudification, and 5G slicing, the cloud core networks tend to be more distributed toward the edge sites. Current distributed radio access networks tend to be more centralized, and the role of fiber optics in cloud RANs (radio access networks) is increasing [17-23]. However, the microwave and millimeter-wave links still continue to form an essential portion of the mobile anyhaul $[1,3,4,6,7,9]$. Business analysts forecast an initial $50 \% / 50 \%$ split of fiber and $\mu / \mathrm{mmW}$ access for $5 \mathrm{G}$. Later on, this split may change to $75 \%$ optical fiber and $25 \%$ radio, when new optical access points-often called PoPs (points of presence) - are added to the networks. This paper focuses on the radio links of the mobile anyhaul. The possible new $\mathrm{mmW}$ frequency bands, the radio link availability targets, and the outage caused by rain are discussed in later sections of the paper.

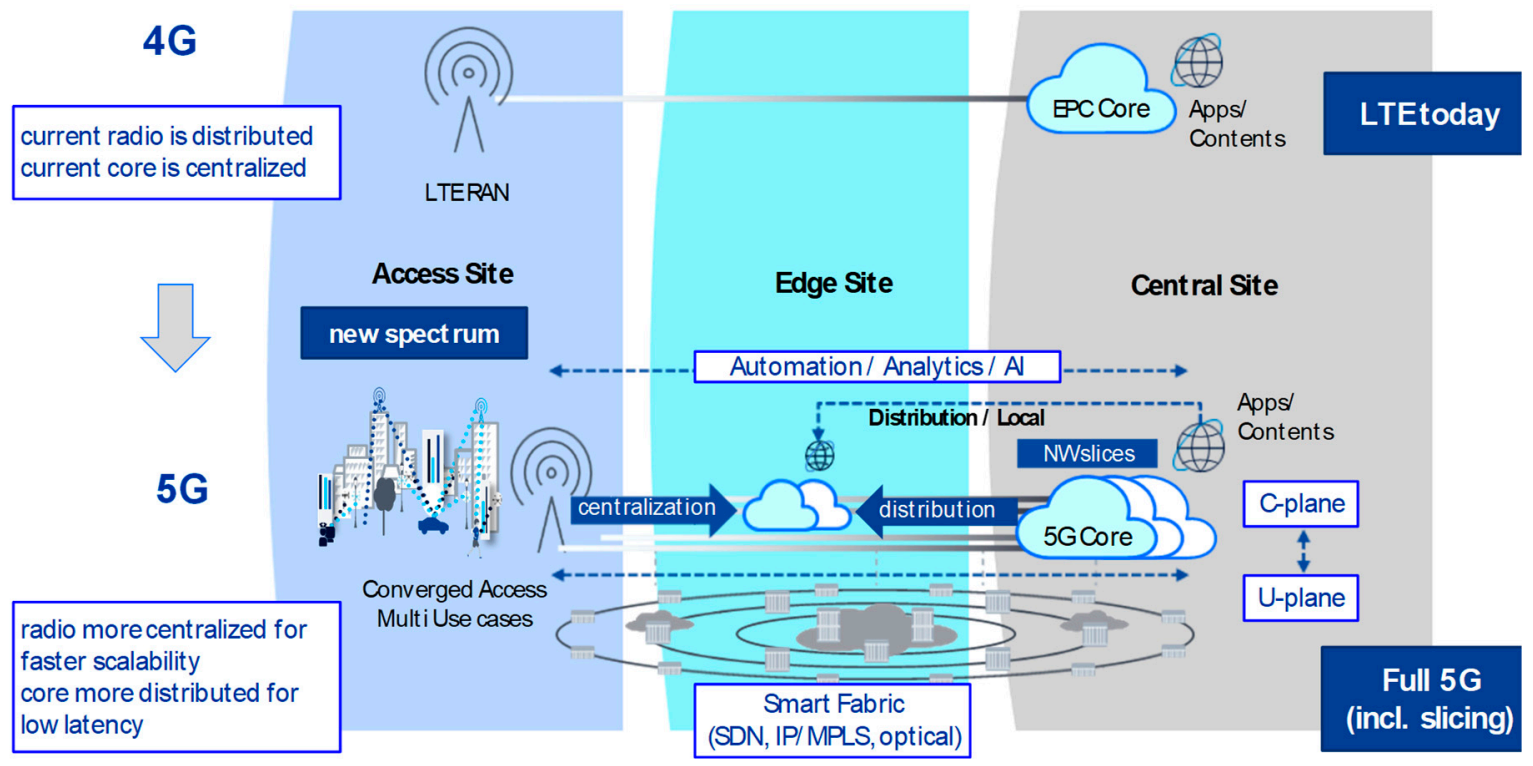

Figure 4. Evolving core and radio access network (RAN) toward cloudification, 5G slicing, and edge sites. 


\section{Higher Link Frequencies and Bit Rates}

As the access links are getting shorter and the capacity demands are increasing continuously, frequencies in millimeter-wave bands are becoming more and more employed [1,4-6,9,11-13]. The millimeter-wave bands V, E, W, and D (57-66, 71-86, 92-114.25, and 130-174.8 GHz, respectively) are coming into focus because wider radio-frequency (RF) bandwidths are available and, as such, the bit rate of the connections is increased and latency is reduced [12-14]. The European Telecommunication Standards Institute (ETSI) discussed the possible frequency bands in Reference [24]. The channel spacing may reach $\mathrm{GHz}$ values, i.e., as a multiple of $250 \mathrm{MHz}$, as seen in Table 1. In the 71-86-GHz bands, the link bit rates go beyond Gbit/s. In the widest 2-GHz RF channel, the link bit rate is above 10 Gbps with equipment from the best equipment class of ETSI [14,24-26].

Table 1. Channel separation and link bit rates in the different frequency bands.

\begin{tabular}{|c|c|c|}
\hline $\begin{array}{l}\text { Frequency Bands } \\
\text { (GHz) }\end{array}$ & $\begin{array}{c}\text { Channel Separation Options }{ }^{1} \\
\text { Minimum; ... ; Maximum (MHz) }\end{array}$ & $\begin{array}{c}\text { Capacities }{ }^{1} \text { According to } \\
\text { Equipment Class and Channel } \\
\text { Separation (Mbit/s) }\end{array}$ \\
\hline 13,15 & $1.75 ; 3.5 ; 7 ; 14 ; 28 ; 56$ & $4-431$ \\
\hline 18 & $1.75 ; 3.5 ; 7 ; 13.75 ; 27.5 ; 55 ; 110$ & $4-862$ \\
\hline $23,26,28,32,38,42$ & $3.5 ; 7 ; 14 ; 28 ; 56 ; 112$ & $4-862$ \\
\hline $50,52,55$ & $3.5 ; 7 ; 14 ; 28 ; 56$ & $2-128$ \\
\hline $\begin{array}{l}57-64,64-66 \\
\text { (V band) }\end{array}$ & $\begin{array}{c}30 \text { or } 50 \text {, multiple of } 30 \text { or } 50, \\
\text { maximum } 2000\end{array}$ & $\begin{array}{c}28.5-3400 \\
\text { (unlicensed band) }\end{array}$ \\
\hline $\begin{array}{l}71,76,81,86 \\
\text { (E band) }\end{array}$ & $\begin{array}{c}62.5 ; 125 ; 250 ; 500 ; 750 ; 1000 ; 1250 \\
1500 ; 1750 ; 2000\end{array}$ & $35-11200$ \\
\hline
\end{tabular}

${ }^{1}$ For more details, see European Telecommunication Standards Institute, ETSI EN 302 217-1 [24].

Please note that there may be deviations from the frequency allocation rules indicated in Table 1 based on local decisions of the national communication authorities. The European Conference of Postal and Telecommunications Administrations (CEPT) already allocates frequencies up to $175 \mathrm{GHz}$ [27-29]. Actual research of fiber/wireless systems goes above $200 \mathrm{GHz}[5,12,19,30]$.

Different methods are utilized to increase the overall transmission capacity of a radio link. A traditional approach is to combine two radio channels operating with different carrier frequencies. Multiple channels operating at different carrier frequencies can also be branched together. Polarization multiplexed links (often simply called "dual-polar" or "cross-polar" links) add up the two different polarizations (i.e., vertical and horizontal) to double the transmission capacity $[13,14,31-34]$. However, dual-polar links require special antennas, and are more sensitive to interference and rain, as discussed in later sections. The combination of cross-polarized and multi-frequency techniques is also well known and widely used. For example, by adding two radio channels (in the same frequency band) and two polarizations, the link capacity can be quadrupled. A novel and interesting approach is to aggregate parallel links operating in different frequency bands to increase capacity. A recent field trial reported an aggregated bit rate of $100 \mathrm{Gbps}$ over microwaves with these techniques [35]. Dual-band antennas are available to combine traditional frequency bands with the $\mathrm{E}$ band $[9,26]$.

\section{Link Parameters and Availability Calculation}

In addition to the climatic and meteorological factors, the availability recommendations for individual links depend on the topology and diversity methods used. Instead of "bulky" hardware-based $1+1$ link protection, in the urban environment, route diversity is recommended [15]. The installation of additional parabolic antennas for link diversity is avoided due to the undesired visual impact. The availability targets are split into site- and link-specific targets. Overall link availability targets are usually given as "four-" or "five-nines". Each radio access link should have, e.g., $A=99.99 \%$ availability over time, including outages due to rain and equipment failures. This $99.99 \%$ availability 
corresponds to an annual outage of approximately $52 \mathrm{~min}$. Outages of the individual links are caused by the following:

- propagation (intensive rain and other atmospheric conditions, such as snow, fog, oxygen, or water vapor absorption at very high frequencies);

- link unavailability due to radio equipment failure.

With reasonable dish sizes, the link unavailability $(U)$ should be $U=0.01 \%$ of the time or less. The link planning guidelines target individual link availability for an annual timeframe that includes the seasonal fluctuations of weather conditions. The goal is to ensure reliable links, regardless of the undesired effects of propagation phenomena and rain. Exceptions may occur, when antenna size is limited due to civil work constraints, e.g., wind load or authorities not permitting the installation of bigger diameter dishes. In the calculations, the frequently used frequency bands are investigated [24]. This paper focuses on rain intensities $R<100 \mathrm{~mm} / \mathrm{h}$ that are typical in Central and Eastern Europe. For completeness, higher rain rates are also calculated, following the rain and propagation model of the International Telecommunication Union, ITU-R P recommendations [36-39].

\subsection{System Gain Calculation}

The International Telecommunication Union (ITU) defines system gain as follows [1,40,41]:

$$
S G(B E R)^{[\mathrm{dB}]}=P_{\mathrm{TX}}{ }^{[\mathrm{dBm}]}-P_{\mathrm{RXth}}(B E R)^{[\mathrm{dBm}]} .
$$

The system gain appropriately characterizes the transmitter and the receiver modules of the digital $\mu \mathrm{W}$ or mmW radio link. Thus, SG helps to determine the maximum distance that the equipment can connect with a given, pre-defined availability. $P_{\mathrm{TX}}$ is the "nominal" transmit power at the output of the transceiver module (point $C / C^{\prime}$ in Figure 5). The reference points are according to the definition of ETSI (as provided in Reference [24]). For simplicity, neither feeder lines nor additional branching are indicated in the figure (for multi-channel or dual-polar links). When there is no feeder or additional branching network, then the transceiver can be directly connected to the transmitting antenna, as plotted in Figure 5. In this case $\left(\mathrm{C}^{\prime}=\mathrm{D}^{\prime}\right)$, the output power $P_{\mathrm{TX}}$ can be measured at the connection point of the antenna $\left(\mathrm{D} / \mathrm{D}^{\prime}\right.$ in Figure 5$)$.

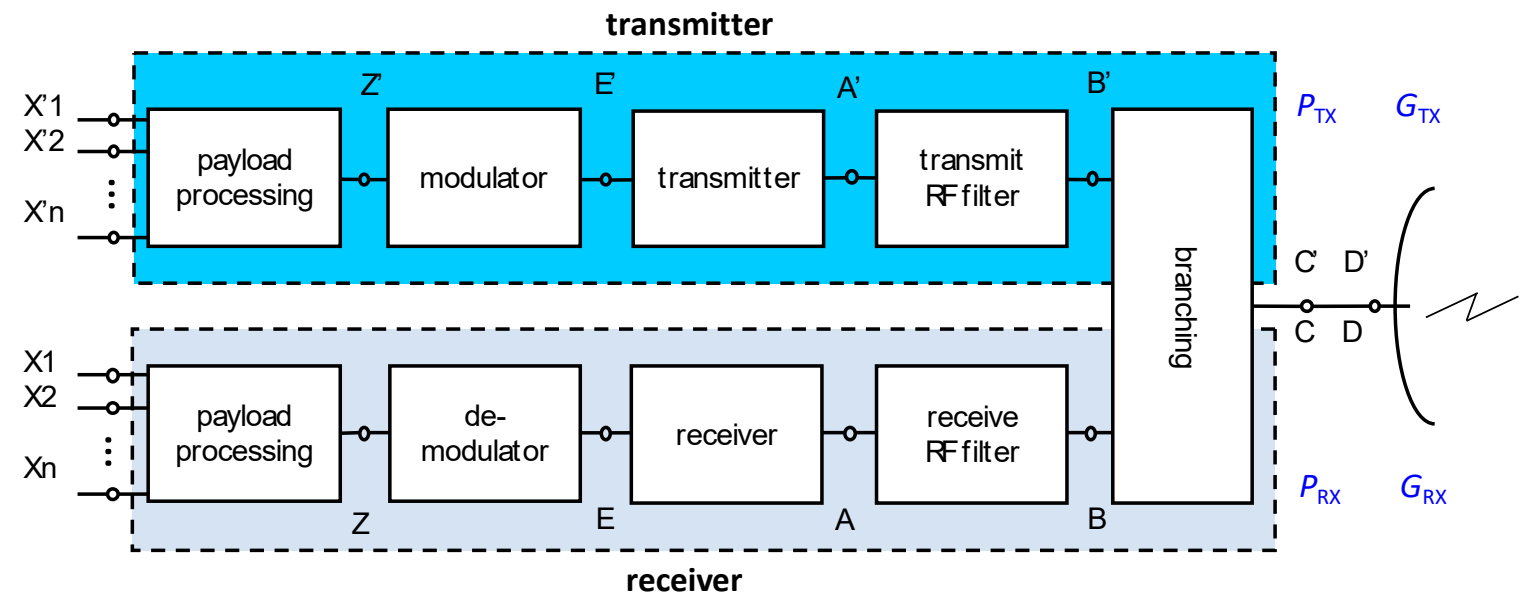

Figure 5. Block diagram of the microwave and millimeter-wave $(\mu / \mathrm{mmW})$ transceiver (without feeder lines), according to European Telecommunication Standards Institute, ETSI EN 302 217. The reference points follow Reference [24].

"Nominal" refers to the fact that, in a wide frequency band and at changing ambient temperatures, variation of a few $\mathrm{dB}$ of the output power may occur and is tolerated [24,42]. The calculations focus on the output power level that is guaranteed at any frequency and temperature within the operational 
range of the outdoor unit (ODU). $P_{\mathrm{RXth}}$ is the receiver sensitivity threshold, i.e., the input power at the receiver that is required for demodulation. Again, if there is no feeder and branching network, then this input power level can be measured directly at the antenna connection point (point $\mathrm{D}$ in Figure 5). In a digital link, the sensitivity threshold of the receiver is defined for a given modulation mode and bit error rate (BER) $[41,43]$. In the case of transceivers capable of adaptive modulation, each modulation mode and the corresponding bit rate has its own set of BER thresholds [10]. In this paper, we use the threshold values belonging to $B E R=10^{-6}$. Please note that $B E R=10^{-3}$ thresholds are also often used. From a system design point of view, any gain due to error correction coding (e.g., FEC, forward error correction) is already considered in the given thresholds.

It is important to mention that an alternative system gain definition also includes the gains of the transmit (TX) and receive (RX) antennas (please see Reference [33]).

$$
S G_{\mathrm{a}}(B E R)^{[\mathrm{dB}]}=P_{\mathrm{TX}}{ }^{[\mathrm{dBm}]}+G_{\mathrm{TX} \mathrm{a}}{ }^{[\mathrm{dBi}]}+G_{\mathrm{RXa}}{ }^{[\mathrm{dBi}]}-P_{\mathrm{RXth}}(B E R)^{[\mathrm{dBm}]},
$$

where $G_{\mathrm{TX}}$ and $G_{\mathrm{RX}}$ stand for the transmit and receive antenna gains, respectively. As indicated with the " $\mathrm{dBi}$ " unit, at microwave and at millimeter-wave frequencies-by definition-the antenna gains are compared to the gain of the isotropic antenna. To distinguish between the two alternative definitions of system gain, in Equation (2), we note $S G_{a}$ to indicate that both $T X$ and $R X$ antenna gains are added already. The two system gain definitions are illustrated in Figure 6 , where only the $\mu / \mathrm{mmW}$ parts are indicated. The payload and modulator/demodulator blocks shown in Figure 5 are not repeated in Figure 6.

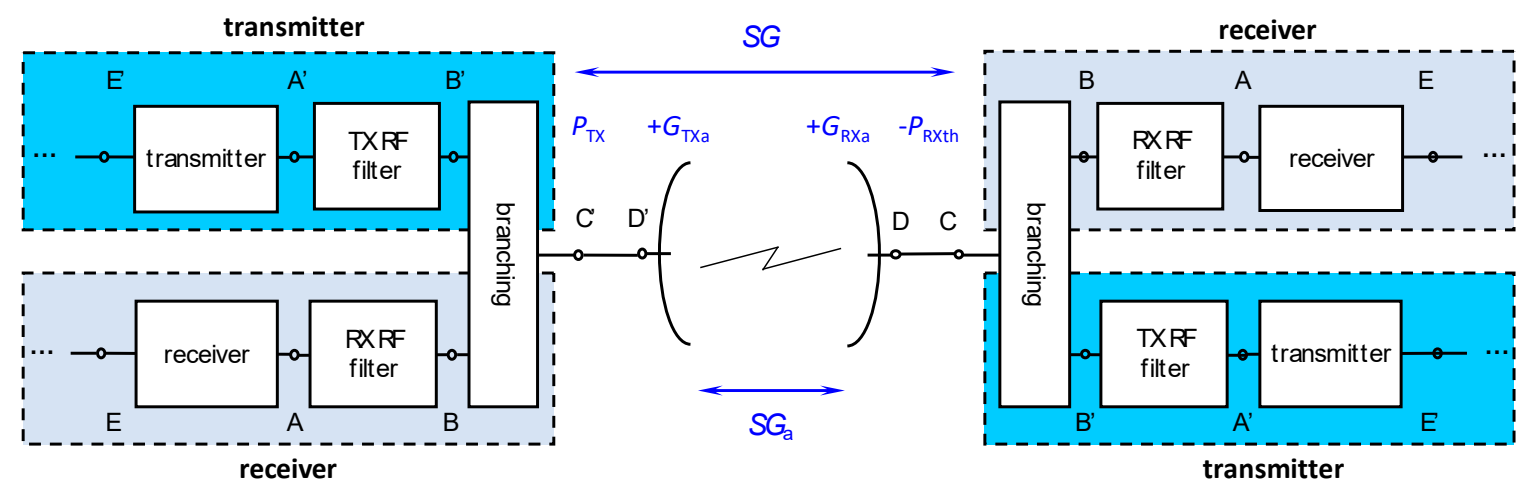

Figure 6. System gain definitions-with and without antennas [1].

Using the alternative system gain definition $S G_{\mathrm{a}}$ is convenient when the transceiver has either an integrated antenna built together with the ODU (Figure 7a) or a flip-mount antenna directly attached to the ODU (Figure 7b). For dual-polarization and multi-channel links, additional signal combiners and/or feeder waveguides are required (Figure $7 \mathrm{c}, \mathrm{d}$ ) that introduce additional losses into the entire system.

A microwave or millimeter-wave link is operational, as long as the system gain is higher than the sum of link losses minus the sum of link gains in a hop.

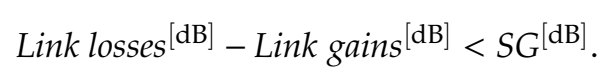

When designing $\mu / \mathrm{mmW}$ links, the network planners should use the $S G$ values carefully, i.e., they must remember which definition is used by the equipment manufacturers when the parameters are specified. The calculation of a complete link is presented in the next section. 


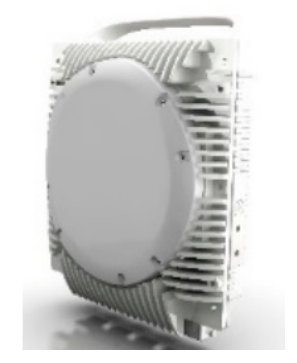

(a)

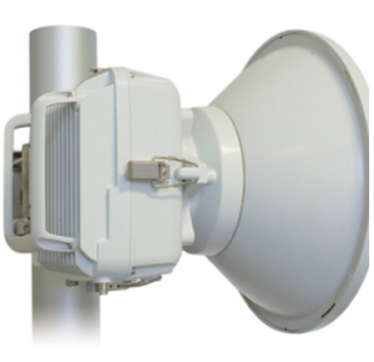

(b)

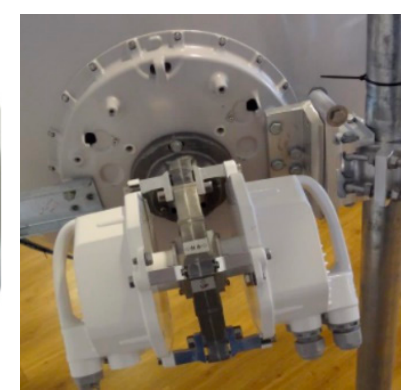

(c)

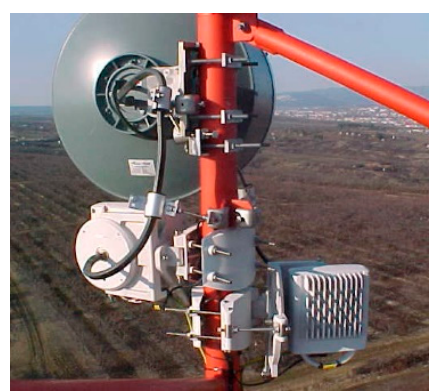

(d)

Figure 7. (a) Integrated antenna assembled as part of the outdoor unit (ODU). (b) Slip-mount antenna fitted without feeder lines to the ODU. (c) Example of combining polarization; photo reproduced with permission from RACOM [34]. (d) Separated antenna with two ODUs and two feeder waveguides.

\subsection{Link Budget and Fading Margin Calculations}

The received signal level (RSL) behind the receiving antenna is calculated as follows [31,41,43]:

$$
P_{\mathrm{RX}}{ }^{[\mathrm{dBm}]}=P_{\mathrm{TX}}{ }^{[\mathrm{dBm}]}+G_{\mathrm{TX}}{ }^{[\mathrm{dBi}]}+G_{\mathrm{RX}}{ }^{[\mathrm{dBi}]}-P L^{[\mathrm{dB}]},
$$

where $P L$ is the propagation loss. With outdoor units integrated with or directly mounted onto the antenna (Figure 7a,b), the waveguide and additional branching loss terms are zero in Equation (4) $[31,40]$. As the link is single-polarized, a polarization combiner between the ODU and the antenna (Figure 7c) is not discussed [34]. The propagation loss $P L$ is calculated as follows:

$$
P L^{[\mathrm{dB}]}=F S L^{[\mathrm{dB}]}+A_{\mathrm{r}}^{[\mathrm{dB}]}+A_{\mathrm{a}}^{[\mathrm{dB}]}+A_{\mathrm{mp}}^{[\mathrm{dB}]}+A_{\mathrm{o}}{ }^{[\mathrm{dB}]} .
$$

In clear LoS conditions, the obstacle loss $A_{\mathrm{o}}$ is zero. At high frequencies, the effect of multipath fading $A_{\mathrm{mp}}$ is usually not relevant, thanks to the very short hops. Typically, in an urban environment, any alternative propagation path is blocked by buildings or other obstacles. Multipath fading is more relevant at lower frequencies (i.e., frequencies at $18 \mathrm{GHz}$ or below) and where reflection from large water surfaces may happen, e.g., propagation over lake or sea. $A_{\mathrm{r}}$ and $A_{\mathrm{a}}$ are the terms of rain and atmospheric attenuation in Equation (5). The unfaded received signal level $P_{\mathrm{RXu}}$ is determined by the free space loss $(F S L)$, the transmitted power $P_{\mathrm{TX}}$, and the gain of the antennas (Figure 8).

$$
P_{\mathrm{RXu}}{ }^{[\mathrm{dBm}]}=P_{\mathrm{TX}}{ }^{[\mathrm{dBm}]}+G_{\mathrm{TX}}{ }^{[\mathrm{dBi}]}+G_{\mathrm{RXa}}{ }^{[\mathrm{dBi}]}-F S L^{[\mathrm{dB}]} .
$$

The free space loss is calculated as follows $[1,31,40]$ :

$$
F S L(f, d)^{[\mathrm{dB}]}=92.44+20 \cdot \log \left(f^{[\mathrm{GHz}]}\right)+20 \cdot \log \left(d^{[\mathrm{km}]}\right),
$$

where $f$ is the frequency of the link, and $d$ is the hop length. The constant of $92.44 \mathrm{~dB}$ allows the calculation in convenient $\mathrm{GHz}$ and $\mathrm{km}$ units for the frequency and distance, respectively. The fade margin $(F M)$ is the difference between the unfaded RSL and the receiver sensitivity threshold.

$$
F M^{[\mathrm{dB}]}=P_{\mathrm{Rxu}}{ }^{[\mathrm{dBm}]}-P_{\mathrm{RXth}}(B E R)^{[\mathrm{dBm}]} .
$$

FM should compensate for all unwanted factors degrading the link availability: rain, fog, dust, snow, atmospheric attenuation, and interference. Interference degrades the sensitivity threshold $P_{\mathrm{RXth}}$ of the receiver. In a sunny scenario, the link can switch to an elevated modulation mode to carry more data. Combining Equations (1), (6), and (8), we get

$$
F M(f, d, \varnothing)^{[\mathrm{dB}]}=S G^{[\mathrm{dB}]}+G_{\mathrm{TX}}{ }^{[\mathrm{dBi}]}+G_{\mathrm{RXa}}{ }^{[\mathrm{dBi}]}-F S L^{[\mathrm{dB}]} .
$$


Equation (9) simplifies to Equation (10) when the transmit and receive antennas have equal gain (i.e., same antenna type and dish size are used at both ends of the link).

$$
F M(f, d, \varnothing)^{[\mathrm{dB}]}=S G^{[\mathrm{dB}]}+2 G_{\mathrm{ant}}{ }^{[\mathrm{dBi}]}-F S L^{[\mathrm{dB}]} .
$$

As seen, at a given frequency, a higher system gain results in a better fade margin of the link for a given $d$ hop length and $\varnothing$ antenna diameter. In mobile front- and backhaul expansion projects (simply "anyhaul" or also called "X-haul" [13,25]), the manufacturer and the type of the radio equipment are usually defined. Thus, parameters $S G, P_{\mathrm{TX}}$, and $P_{\mathrm{RX} \text { th }}$ are given and cannot be selected freely. In several projects, for example, it is expected to re-use the equipment running in the field. Only few parameters remain free for the planners in practice, when the new links in the network are designed. In the planning phase, therefore, both the frequency band $f$ and the antenna diameters should be carefully selected for a given hop length $d$. Lower frequencies are more "valuable" and should be reserved for long-haul links. For simultaneously reducing the undesired radio interference [43] and increasing the FM, preferably bigger dish diameters and the use of ATPC are recommended.

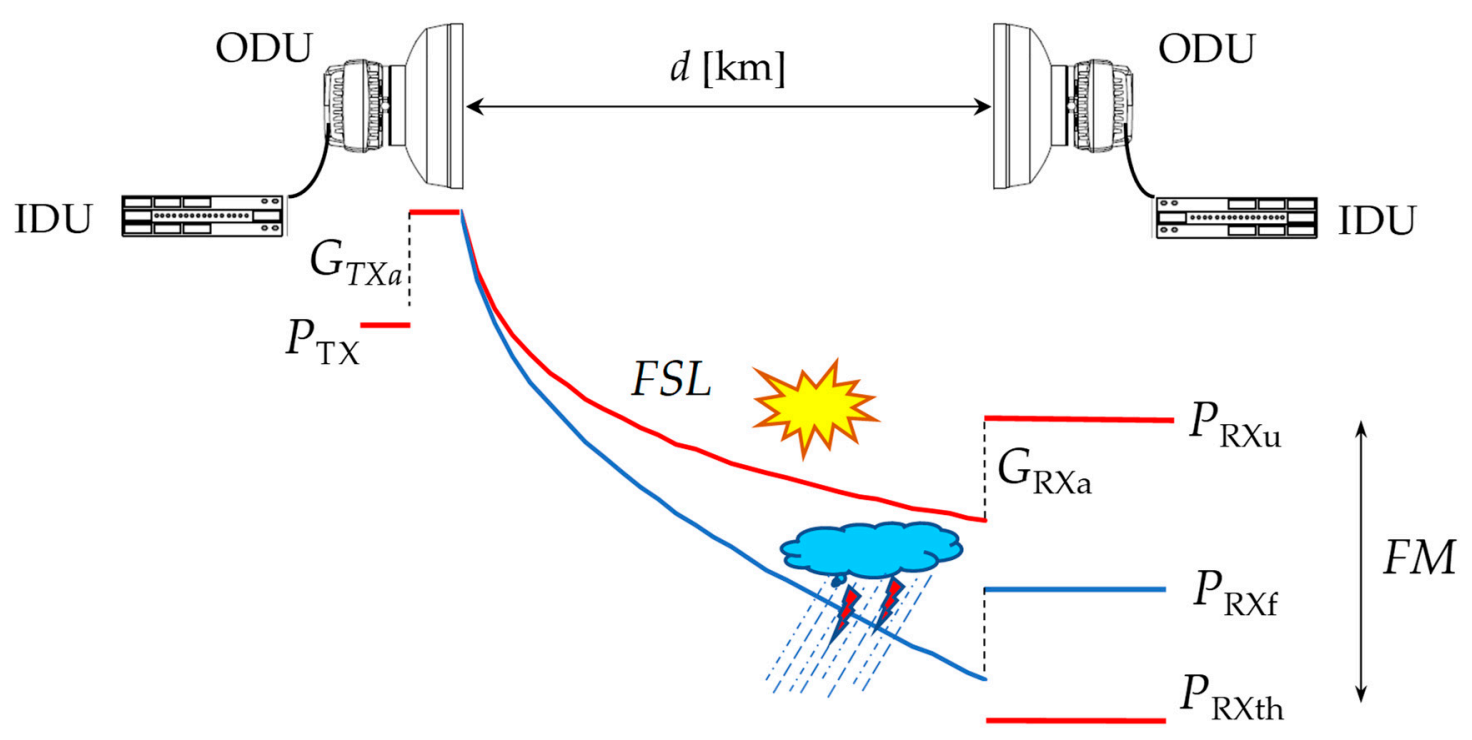

Figure 8. Link budget and fading margin calculation.

Radio links using adaptive modulation have different $P_{\mathrm{R} X \mathrm{th}}$ thresholds for the different modulation modes (Figure 9). The low modulation mode is active in the rainy minutes when FM compensates for the loss caused by rain. During sunny periods when the $F M$ is available, the link can jump to elevated modulation modes; thus, more data can be transmitted [1,11,31-34]. For simplicity, Figure 9 shows quadrature amplitude modulation (QAM) only up to the 512 states [10]. State-of-the-art transceivers can use up to 4096-QAM to reach multi Gigabit/s bit rates as discussed in Section 3.

Finally, the link is operational as long as its fade margin is greater than the losses caused by the rain and by the atmospheric attenuation (obstacle losses and interference are not considered).

$$
F M^{[\mathrm{dB}]}>A_{\mathrm{r}, 0.01 \%}{ }^{[\mathrm{dB}]}+A_{\mathrm{a}}{ }^{[\mathrm{dB}]} .
$$




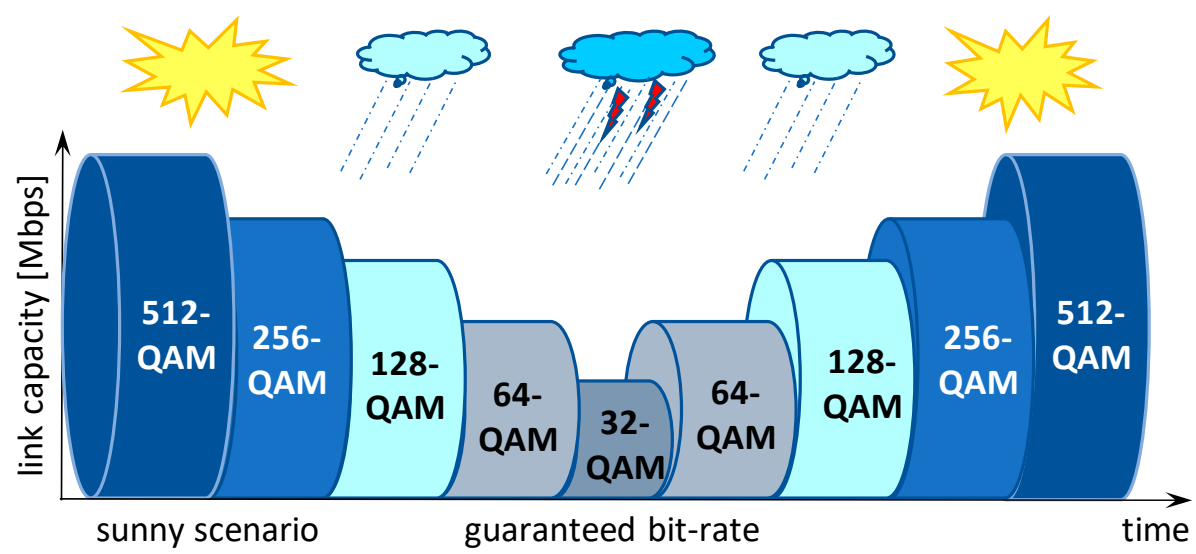

Figure 9. Adaptive link modulation when ensuring guaranteed bit rate during intensive rain.

\subsection{Rain and Atmospheric Attenuation}

The rain attenuation calculation follows the methodology discussed in ITU-R P.530 [36-38]. The rain attenuation term $A_{0.01 \%}$ refers to the attenuation that is exceeded for $0.01 \%$ of the time and caused by intensive rainfall. This rain attenuation-exceeded in $0.01 \%$ of the time-is given as

$$
A_{0.01 \%}[\mathrm{~dB}]=\gamma_{\mathrm{R}} d_{\mathrm{eff}}=\gamma_{\mathrm{R}} \frac{d}{1+d / d_{0}} .
$$

In Equation (12), $\gamma_{\mathrm{R}}$ is the specific attenuation (in $\mathrm{dB} / \mathrm{km}$ ) due to rain, and $d_{\text {eff }}$ is the effective hop length.

$$
d_{\mathrm{eff}}=\frac{d}{1+d / d_{0}} .
$$

When the rain rate is $R_{0.01 \%} \leq 100 \mathrm{~mm} / \mathrm{h}$, then

$$
d_{0}=35 e^{-0.015 R_{0.01 \%}}
$$

When $R_{0.01 \%}>100 \mathrm{~mm} / \mathrm{h}$, then $d_{0}=35 \times e^{-1.5}$ (i.e., $R=100 \mathrm{~mm} / \mathrm{h}$ is used for all rain rates above $100 \mathrm{~mm} / \mathrm{h}$ ). However, such intensive rain is not relevant in the Central and Eastern Europe region [37]. According to ITU-R P.838, the specific attenuation for vertical polarization is calculated as follows:

$$
\gamma_{\mathrm{R}, \mathrm{V}}=k_{\mathrm{V}} R^{\alpha_{\mathrm{V}}}
$$

and that for horizontal polarization is calculated as follows:

$$
\gamma_{\mathrm{R}, \mathrm{H}}=k_{\mathrm{H}} R^{\alpha_{\mathrm{H}}},
$$

where the constants $k_{\mathrm{V}}, \alpha_{\mathrm{V}}, k_{\mathrm{H}}$, and $\alpha_{\mathrm{H}}$ depend on the frequency $f$ and the polarization of the link [38]. $\mathrm{V}$ and $\mathrm{H}$ stand for vertical and horizontal polarization, respectively.

The atmospheric attenuation, $A_{\mathrm{a}}$, is caused by the absorption of gaseous particles in the air. Compared to rain attenuation $\left(A_{\mathrm{r}, 0.01 \%}\right.$ in Equation (11)), for few-km short hops, $A_{\mathrm{a}}$ is negligibly small in most of the frequency bands used by $\mu / \mathrm{mmW}$ links. As seen in Figure 10, up to $300 \mathrm{GHz}$, there are four remarkable attenuation peaks [39]. Water vapor causes extra attenuation in the $23 \mathrm{GHz}$ band (where $A_{\mathrm{sp}}=0.2 \mathrm{~dB} / \mathrm{km}$ ) and around $180 \mathrm{GHz}$. 


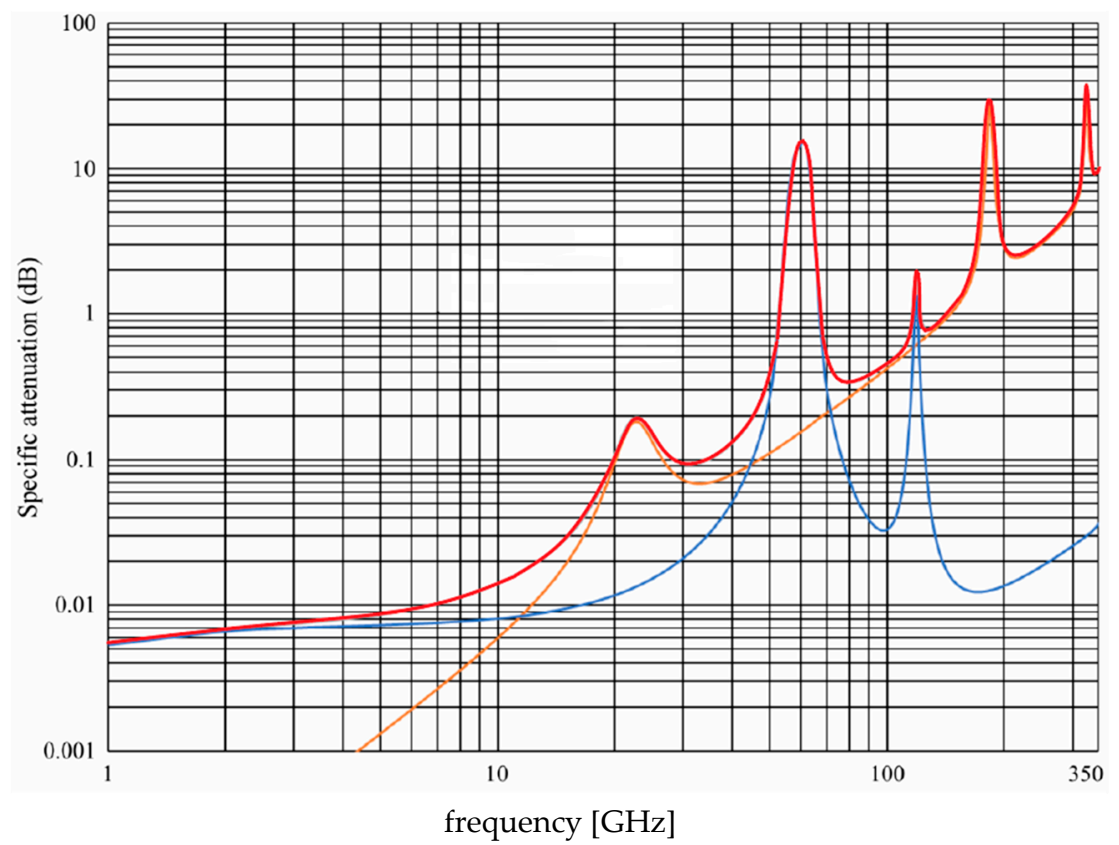

Figure 10. Specific attenuation due to oxygen (blue line), water vapor (orange line), and total attenuation (red line) according to International Telecommunication Union, ITU-R P.676-12. Reproduced with permission from ITU [39].

Other high attenuation peaks are caused by oxygen absorption in the $56-64 \mathrm{GHz}$ and in the $120 \mathrm{GHz}$ range $[39,44,45]$. As seen in Figure 11, the attenuation due to oxygen absorption is very high: about $A_{\mathrm{sp}}=13-15 \mathrm{~dB} / \mathrm{km}$ in the $58-62-\mathrm{GHz}$ band. Therefore, the $57-63 \mathrm{GHz}$ links are limited to a few hundred meters, and the use of vertical polarization is recommended $[44,45]$. On the other hand, at 56-64 GHz, due to the very high atmospheric attenuation, the chance for interference from other links is rather small, enabling severe frequency re-use. The 30 or $50 \mathrm{MHz}$ bands are allocated by CEPT in this range, as listed in Table 1.

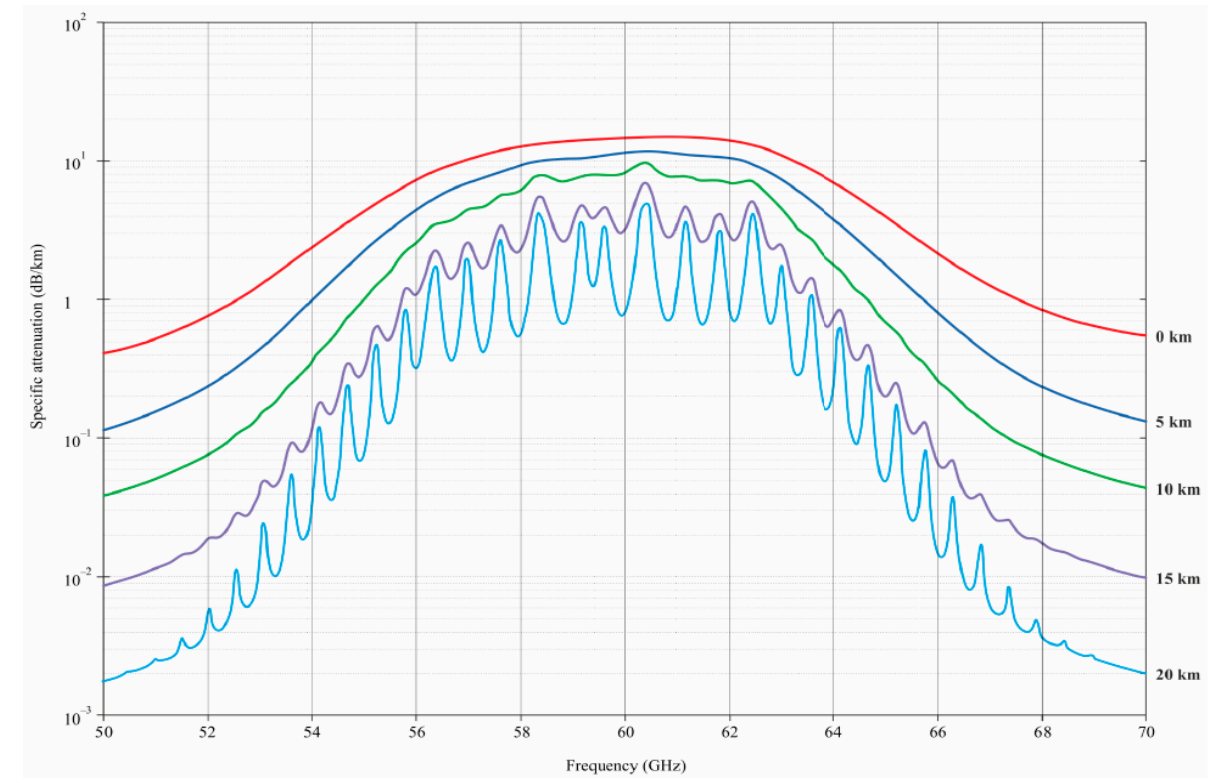

Figure 11. Atmospheric attenuation at $50-70 \mathrm{GHz}$ (in $\mathrm{dB} / \mathrm{km}$, red line: sea level), according to ITU-R P.676-12. Reproduced with permission from ITU [39]. 
For the frequently used bands, Table 2 summarizes the typical atmospheric attenuation values per $\mathrm{km}$ (at sea level). These values are used in the calculations.

Table 2. Atmospheric attenuation at different frequencies.

\begin{tabular}{ccccccccccccc}
\hline Frequency Band $(\mathrm{GHz})$ & $\mathbf{1 3}$ & $\mathbf{1 5}$ & $\mathbf{1 8}$ & $\mathbf{2 3}$ & $\mathbf{2 8}$ & $\mathbf{3 2}$ & $\mathbf{3 8}$ & $\mathbf{5 8}$ & $\mathbf{6 0}$ & $\mathbf{8 0}$ & $\mathbf{9 0}$ & $\mathbf{1 0 0}$ \\
\hline $\begin{array}{c}\boldsymbol{A}_{\boldsymbol{s p}} \text {, atmospheric } \\
\text { attenuation }(\mathrm{dB} / \mathbf{k m})\end{array}$ & 0.02 & 0.03 & 0.07 & 0.2 & 0.1 & 0.09 & 0.13 & 13 & 15 & 0.36 & 0.4 & 0.45 \\
\hline
\end{tabular}

For the entire link distance $d$, the total gaseous attenuation caused by water vapor and oxygen is calculated as follows:

$$
A_{\mathrm{a}}{ }^{[\mathrm{dB}]}=A_{\mathrm{sp}}{ }^{[\mathrm{dB} / \mathrm{km}]} \cdot \mathrm{d}^{[\mathrm{km}]} .
$$

The atmospheric attenuation per $\mathrm{km}, A_{\mathrm{sp}}$, is shown together with rain attenuation in Figure $12 \mathrm{up}$ to $200 \mathrm{GHz}[12,30,32]$. As seen, between $64 \mathrm{GHz}$ and $120 \mathrm{GHz}$, there is a useful frequency "window" where new $\mathrm{mmW}$ links can benefit from a wide spectrum with atmospheric attenuation below $1 \mathrm{~dB} / \mathrm{km}$. Also, as seen in Figure 12, rain attenuation is dominant at all frequencies, except for 60, 120, and $180 \mathrm{GHz}$, where the atmospheric attenuation peaks are visible even when the rainfall rate is above $20 \mathrm{~mm} / \mathrm{h}$.

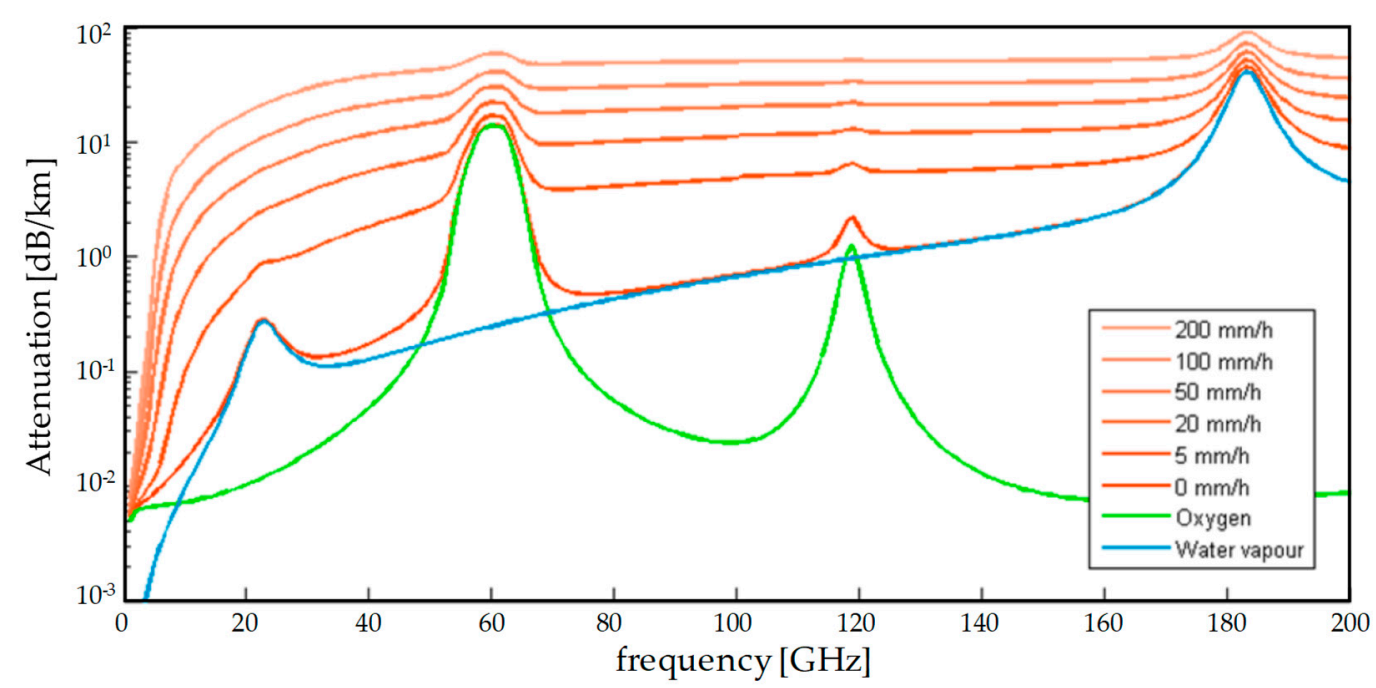

Figure 12. Combined atmospheric and rain attenuation in $\mathrm{dB} / \mathrm{km}$ as a function of frequency [12]. The figure is re-printed with the permission of ETSI.

Equation (11) has no closed-form solution. After inserting the rain and atmospheric attenuation formulas (Equations (12)-(17)) into Equation (11), the maximum hop length $d$ can be calculated numerically for a given $R_{0.01 \%}$ rainfall rate, polarization (either $\mathrm{V}$ or $\mathrm{H}$ ), and frequency $f$.

$$
S G+2 G_{\mathrm{ant}}>92.44+20 \log (f)+20 \log (d)+k_{\mathrm{V} / \mathrm{H}} R^{\alpha_{\mathrm{V} / \mathrm{H}}} \frac{d}{1+d / 35 e^{-0.015 R_{0.01 \%}}}+A_{\mathrm{sp}} d,
$$

where $f$ is in $\mathrm{GHz}$ and $d$ is in $\mathrm{km}$ units. The $S G, G_{\text {ant }}$, and all the attenuation terms are in $\mathrm{dB}$. Index $\mathrm{V} / \mathrm{H}$ shows that parameters $k$ and $\alpha$ are different for the two polarizations. In Section 5 , systematic calculation results are given for typical system values considered in dense access networks.

\subsection{Obstacle Losses}

By careful link design and installation, any unwanted extra loss should be avoided, to preserve the highest possible fade margin for the link. Microwave and millimeter-wave links require clean 
line-of-sight conditions that are checked in the planning phase of the links in two ways. The first method is to use digital maps, digital terrain, and clutter models in the link planning tool. The second method-not to be forgotten-involves site visits, where the LoS of the planned link is confirmed and photographed. It is strongly recommended to always document the clean LoS in an LoS report and to insert the confirmed LoS paths into the planning tool (green lines in Figure 3). With actual high-performing digital cameras, links of $50 \mathrm{~km}$ or even longer can be checked. Later, trees (Figure 13b), new buildings, cranes, electric cables, or chimneys may block the link. As a rule of thumb, at least, the first Fresnel zone of the link should be clean [32,41]. However, in some urban environments, the obstacle loss cannot be avoided, e.g., when the link must operate behind window lamels or camouflage to reduce the visual impact of the antenna (Figure 13c). In such cases, the extra loss caused by the obstacle (Figure 13) should be taken into account in the link budget calculation (Equation (5)).

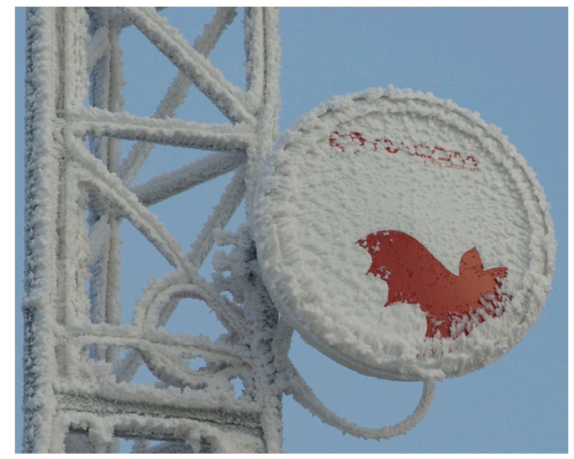

(a)

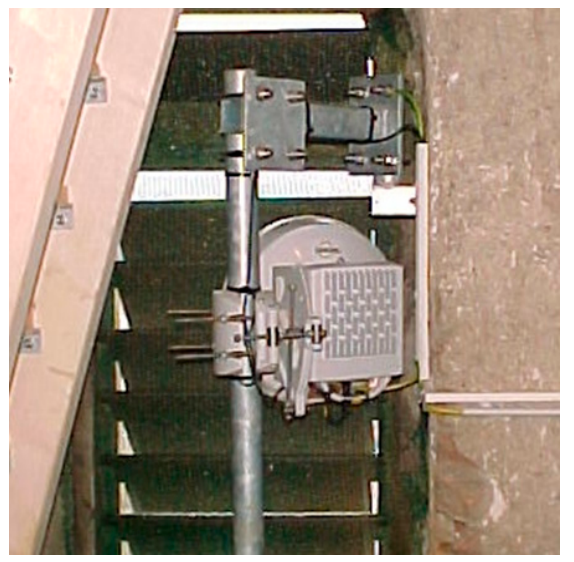

(c)

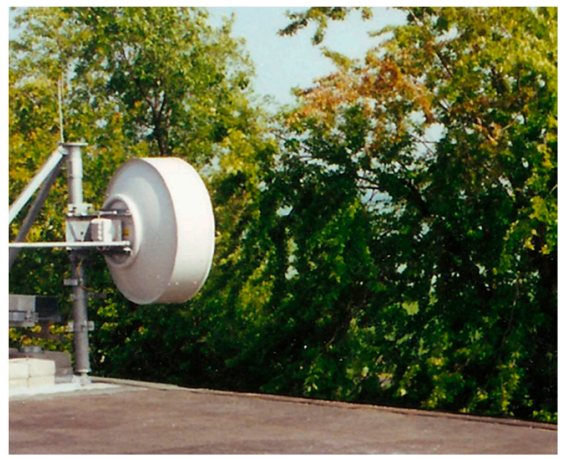

(b)

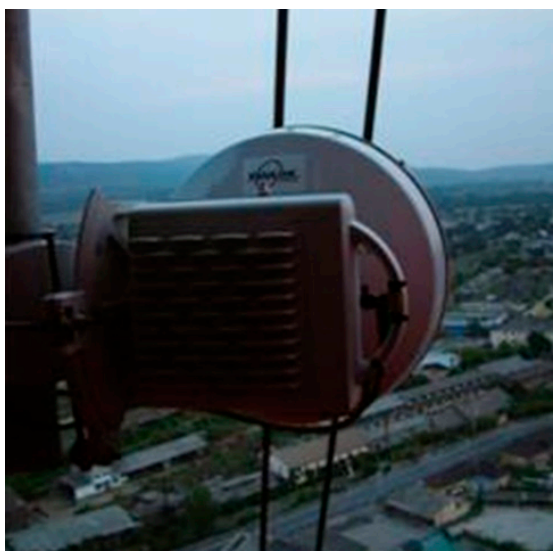

(d)

Figure 13. (a) Ice and snow on the radome of a parabolic dish; the photo is re-printed with permission from RACOM [34]. (b) Extra attenuation due to a tree in the near field. (c) ODU installed behind a church window (polycarbonate lamels). (d) Metal cables inside the first Fresnel zone of the $\mu \mathrm{W}$ link.

\section{Results and Calculation Examples}

Results of systematic hop-length calculations for short- and medium-haul digital $\mu / \mathrm{mmW}$ point-to-point links are presented in this section. Solving Equation (18), the recommended maximum distances were calculated. All the links operate in ETSI-defined communication bands widely used in Europe, at frequencies of $13,15,18,23,26,28,32,38,58$, and $80 \mathrm{GHz}$. Up to $38 \mathrm{GHz}$, the links in the calculations used $14 \mathrm{MHz}$ channel spacing (ETSI and ITU channel raster) and 32-TCM (trellis coded modulation) for $34 \mathrm{Mbit} / \mathrm{s}[10,24]$. The $58 \mathrm{GHz}$ links used $50 \mathrm{MHz}$ channel spacing. The transmitters were set to the highest output power and the links had identical antenna size on both ends. The main parameters of the calculated links are summarized in Tables 3 and 4. In the 13-38 $\mathrm{GHz}$ bands, slip-mounted $60 \mathrm{~cm}$ - and $30 \mathrm{~cm}$-diameter parabolic dishes are used (marked with ø). At 
$58 \mathrm{GHz}$, $\varnothing 0 \mathrm{~cm}$ parabolic dishes and integrated $20 \mathrm{~cm}$ rectangular antennas are used (marked with ㅁ). The integrated rectangular $58 \mathrm{GHz}$ antenna is a grid composed of radiating waveguide elements. The low-profile antenna structure and its measurement are discussed in Reference [46]. The system and antenna gain values are illustrative examples. Naturally, the simulation can also run with different $S G$ values and with asymmetric antenna configuration.

Table 3. Transmit power, antenna gain, and receiver threshold of the calculated $13-38 \mathrm{GHz}$ links. BER-bit error rate.

\begin{tabular}{|c|c|c|c|c|c|c|}
\hline \multirow{2}{*}{$\begin{array}{c}\text { Frequency } \\
\text { Band } \\
(\mathrm{GHz})\end{array}$} & \multirow{2}{*}{$\begin{array}{c}\text { Nominal } \\
P_{\mathrm{TX}} \\
(\mathrm{dBm})\end{array}$} & \multirow{2}{*}{$\begin{array}{c}G_{\text {ant }} \\
\text { б } 30 \mathrm{~cm} \\
(\mathrm{dBi}) 1,2\end{array}$} & \multirow{2}{*}{$\begin{array}{c}G_{\text {ant }} \\
\text { ø } 60 \mathrm{~cm} \\
(\mathrm{dBi}) 1,3\end{array}$} & \multirow{2}{*}{$\begin{array}{c}P_{\mathrm{RXth}} \text { at } \\
B E R=10^{-6} \\
(\mathrm{dBm})\end{array}$} & \multicolumn{2}{|c|}{$S G_{a}=S G+2 G_{\mathrm{ant}}$} \\
\hline & & & & & $\begin{array}{c}\sigma 30 \mathrm{~cm} \\
\text { (dB) }\end{array}$ & $\begin{array}{c}\text { ø } 60 \mathrm{~cm} \\
\text { (dB) }\end{array}$ \\
\hline 13 & 20 & 30.9 & 35.8 & -74 & 155.8 & 165.6 \\
\hline 15 & 18 & 32.1 & 36.8 & -76 & 158.2 & 167.6 \\
\hline 18 & 18 & 34.2 & 38.7 & -73 & 159.4 & 168.4 \\
\hline 23 & 18 & 35.3 & 40.4 & -75 & 163.6 & 173.8 \\
\hline 26 & 18 & 36.6 & 41.2 & -73 & 164.2 & 173.4 \\
\hline 28 & 16 & 38.1 & 42.2 & -72 & 164.2 & 172.4 \\
\hline 32 & 16 & 38.9 & 43.7 & -72 & 165.8 & 175.4 \\
\hline 38 & 16 & 40.1 & 45.2 & -73 & 169.2 & 179.4 \\
\hline
\end{tabular}

${ }^{1}$ Antennas in the calculations are ValuLine from Andrew, a CommScope Company. ${ }^{2}$ The physical size of the $30-\mathrm{cm}$ (one foot) antenna is $39 \mathrm{~cm}$ (outer diameter). ${ }^{3}$ The physical size of the $60-\mathrm{cm}$ (two feet) antenna is $69 \mathrm{~cm}$ (outer diameter) $[47,48]$.

Table 4. Transmit power, antenna gain, and receiver threshold of the calculated $58 \mathrm{GHz}$ links.

\begin{tabular}{|c|c|c|c|c|c|c|}
\hline \multirow{2}{*}{$\begin{array}{c}\text { Frequency } \\
\text { Band } \\
(\mathrm{GHz})\end{array}$} & \multirow{2}{*}{$\begin{array}{c}\text { Nominal } \\
P_{\mathrm{TX}} \\
(\mathrm{dBm})\end{array}$} & \multirow{2}{*}{$\begin{array}{c}G_{\text {ant }} \\
\square 20 \mathrm{~cm} \\
(\mathrm{dBi})\end{array}$} & \multirow{2}{*}{$\begin{array}{c}G_{\text {ant }} \\
\text { o } 30 \mathrm{~cm} \\
(\mathrm{dBi})\end{array}$} & \multirow{2}{*}{$\begin{array}{c}P_{\mathrm{RXth}} \text { at } \\
B E R=10^{-6} \\
(\mathrm{dBm})\end{array}$} & \multicolumn{2}{|c|}{$S G_{a}=S G+2 G_{\mathrm{ant}}$} \\
\hline & & & & & $\begin{array}{c}\square 20 \mathrm{~cm} \\
(\mathrm{~dB})\end{array}$ & $\begin{array}{c}\text { ø } 30 \mathrm{~cm} \\
\text { (dB) }\end{array}$ \\
\hline 58 & 5 & 36 & 41.5 & -74 & 146 & 157 \\
\hline
\end{tabular}

The graphs in Figures 14 and 15 were drawn using the rain model according to ITU-R P.838 [38]. The shadowed regions show typical rainfall rates in Central and Eastern Europe, $(\mathrm{H}$ and $\mathrm{K}$ rain zones according to ITU-R P.837 [37]). The curves were calculated without any additional obstacle loss (Figure 13). Single-polarized links were calculated, and there was no polarization combiner loss calculated in the link budget. Antennas were directly connected to the transceivers, thus no waveguide losses were considered due to feeder lines. Vertical polarization is shown in Figures 14a and 15a. Horizontal polarization is shown in Figure 14b and in Figure 15b. As earlier discussed in Section 4, at $58 \mathrm{GHz}$ frequency, the atmospheric attenuation is very high. Therefore, horizontal polarization is not recommended, and only vertical polarization is calculated $[44,45,49]$. Note that $7-15 \mathrm{GHz}$ links are rarely used in a dense urban environment. For the 13-18 GHz links, the minimum recommended dish diameter is $60 \mathrm{~cm}$. Several communication authorities specify very strict antenna pattern requirements for the lower frequency bands to avoid interference (e.g., minimum antenna gain, maximum sidelobe, front-to-back ratio) [50]. In practice, the $30 \mathrm{~cm}$ dishes are not permitted in the frequency bands below $18 \mathrm{GHz}$ in some countries to achieve better frequency re-use. Therefore, the calculated 13-18 GHz links with $30 \mathrm{~cm}$ dishes are shown only for comparison (the upper three curves in Figure 15a,b).

Finally, calculation results are shown for the $\mathrm{E}$ band. In the examples, the parameters of the Nokia millimeter-wave radio family are used, as given in Table 5. The "Wavence" radios can operate with several channel spacing options at $80 \mathrm{GHz}: 62.5 \mathrm{MHz}, 125 \mathrm{MHz}, 250 \mathrm{MHz}, 500 \mathrm{MHz}, 750 \mathrm{MHz}, 1 \mathrm{GHz}$, 1.25 GHz, $1.5 \mathrm{GHz}$, and $2 \mathrm{GHz}$. The $80 \mathrm{GHz}$ radio uses adaptive modulation up to 256-QAM. 


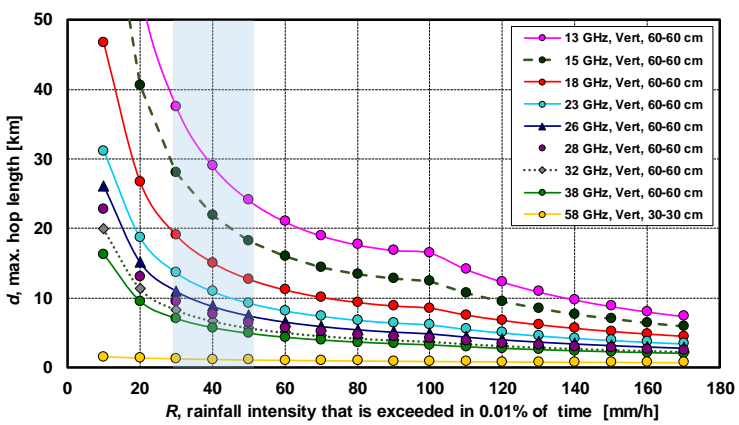

(a)

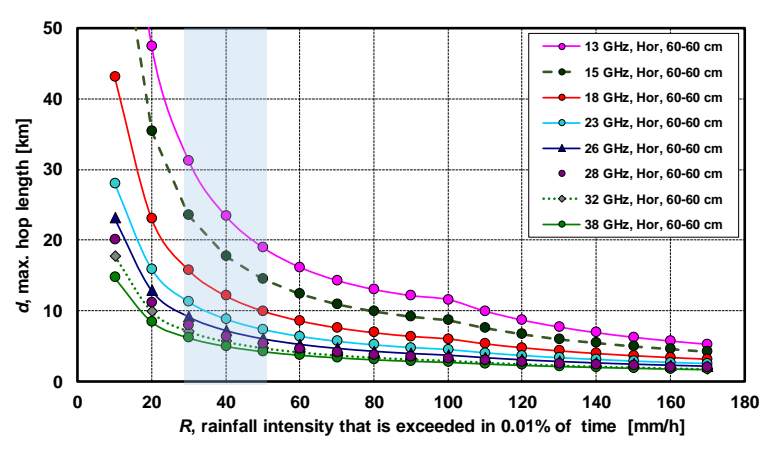

(b)

Figure 14. Recommended hop lengths as a function of rainfall intensity. (a) Hops with vertical polarization, $34 \mathrm{Mbit} / \mathrm{s}, 14 \mathrm{MHz}$, and $\varnothing 60 \mathrm{~cm}$ dishes. For the $58 \mathrm{GHz}$ link, ø $30 \mathrm{~cm}$ dishes are used in the calculations. (b) Hops with horizontal polarization, $34 \mathrm{Mbit} / \mathrm{s}, 14 \mathrm{MHz}$, and $\varnothing 60 \mathrm{~cm}$ dishes.

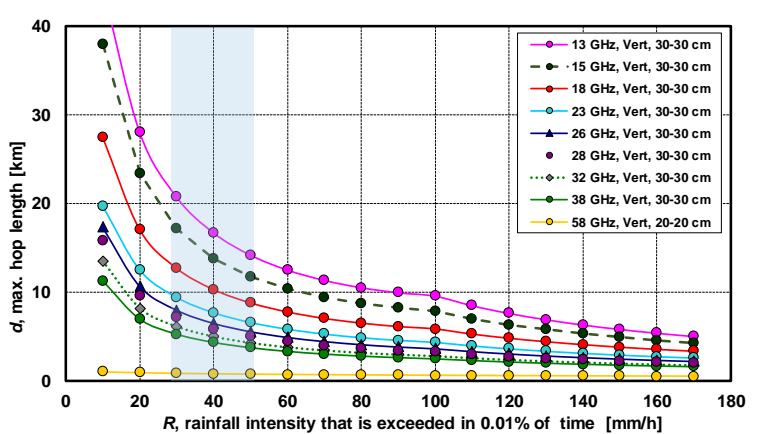

(a)

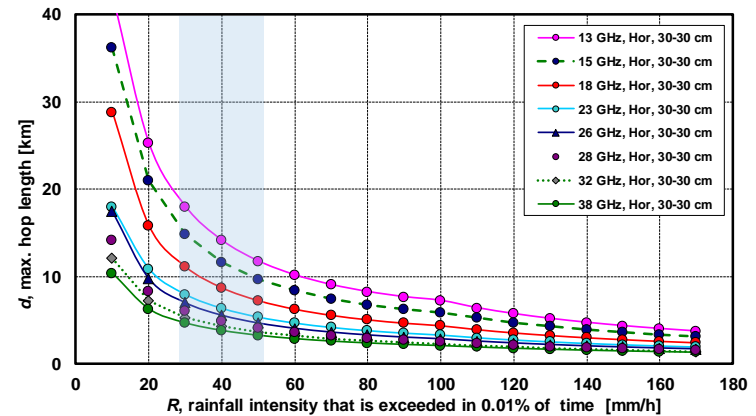

(b)

Figure 15. Recommended hop lengths as a function of rainfall intensity. (a) Hops with vertical polarization, $34 \mathrm{Mbit} / \mathrm{s}, 14 \mathrm{MHz}$, and $\varnothing 30 \mathrm{~cm}$ dishes. In the $58 \mathrm{GHz}$ band, $\square 20 \mathrm{~cm}$ rectangular antennas are used. (b) Hops with horizontal polarization, $34 \mathrm{Mbit} / \mathrm{s}, 14 \mathrm{MHz}$, and ø $30 \mathrm{~cm}$ dishes.

Table 5. Transmit power, antenna gain and receiver threshold of the calculated $80 \mathrm{GHz}$ links. BPSK—-binary phase-shift keying; QPSK—quadrature phase-shift keying; QAM-quadrature amplitude modulation.

\begin{tabular}{|c|c|c|c|c|c|c|c|c|}
\hline \multirow{2}{*}{$\begin{array}{l}\text { Modulation } \\
\text { Mode }\end{array}$} & \multirow{2}{*}{$\begin{array}{c}\text { Nominal } \\
P_{\mathrm{TX}} \\
(\mathrm{dBm})\end{array}$} & \multirow{2}{*}{$\begin{array}{c}G_{\text {ant }} \\
\sigma 12 \mathrm{~cm} \\
\text { (dBi) }\end{array}$} & \multirow{2}{*}{$\begin{array}{c}G_{\text {ant }} \\
\text { o } 39 \mathrm{~cm} \\
(\mathrm{dBi})\end{array}$} & \multirow{2}{*}{$\begin{array}{c}G_{\text {ant }} \\
\sigma 69 \mathrm{~cm} \\
(\mathrm{dBi})\end{array}$} & \multirow{2}{*}{$\begin{array}{c}P_{\mathrm{RXth}} \text { at } \\
B E R=10^{-6} \\
(\mathrm{dBm})\end{array}$} & \multicolumn{3}{|c|}{$S G_{a}=S G+2 G_{\mathrm{ant}}$} \\
\hline & & & & & & $\begin{array}{l}\text { б } 12 \mathrm{~cm} \\
\text { (dB) }\end{array}$ & $\begin{array}{c}\text { б } 39 \mathrm{~cm} \\
(\mathrm{~dB})\end{array}$ & $\begin{array}{l}\text { o69 cm } \\
\text { (dB) }\end{array}$ \\
\hline BPSK $1 / 4$ & 16 & \multirow{8}{*}{38} & \multirow{8}{*}{43.1} & \multirow{8}{*}{50.9} & -76.4 & 168.4 & 178.6 & 194.2 \\
\hline BPSK $1 / 2$ & 16 & & & & -73.4 & 165.4 & 175.6 & 191.2 \\
\hline BPSK & 16 & & & & -70.4 & 162.4 & 172.6 & 188.2 \\
\hline QPSK & 16 & & & & -67.4 & 159.4 & 169.6 & 185.2 \\
\hline 16-QAM & 14 & & & & -60.8 & 150.8 & 161.0 & 176.6 \\
\hline 32-QAM & 14 & & & & -57.7 & 147.7 & 157.9 & 173.5 \\
\hline 64-QAM & 13.5 & & & & -55.2 & 144.7 & 154.9 & 170.5 \\
\hline 128-QAM & 12.5 & & & & -51.8 & 140.3 & 150.5 & 166.1 \\
\hline
\end{tabular}

In the calculations, $1 \mathrm{GHz}$ RF bandwidth was selected. Three antenna configurations and different modulation modes were compared (from binary phase-shift keying (BPSK) to 128-QAM). The ø 12-cm antenna was integrated with the ODU (see Figure 7a). The one-foot and two-foot antennas were slip-mounted. Figure 16 plots the calculation results. As seen, depending on the antenna size and modulation used, the links can operate in distances of $1-4 \mathrm{~km}$ with $A=99.99 \%$ availability in the $\mathrm{K}$ rain zone. Calculations show that the predicted behavior is very similar for horizontal and vertical polarization in the E band (Figure 16d), which needs to be experimentally verified by long-term measurements. Finally, the curves, such as that shown in Figure 16e, help to decide the minimum 
required modulation mode and, as such, the bit rate that a link can support in the case of intensive rain for a given hop length. The continuous monitoring of radio RSL and modulation mode is supported by Wavence radios, as illustrated in the example of Figure 16f.

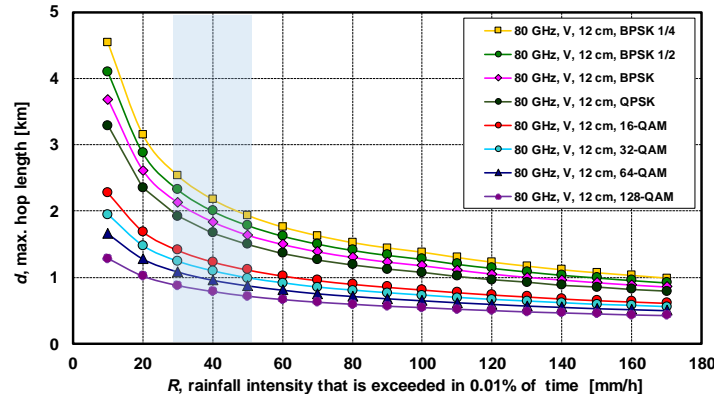

(a)

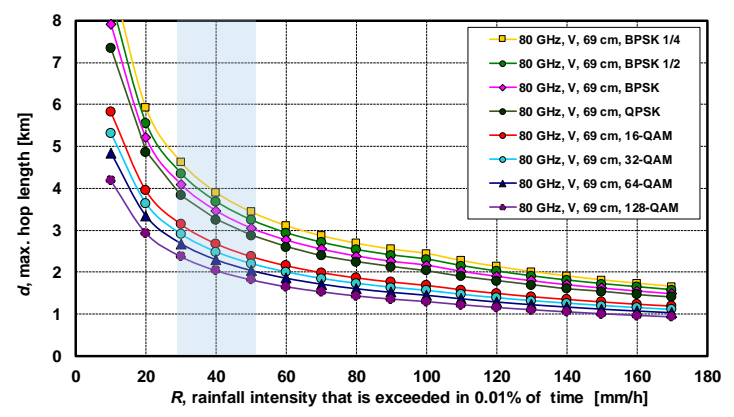

(c)

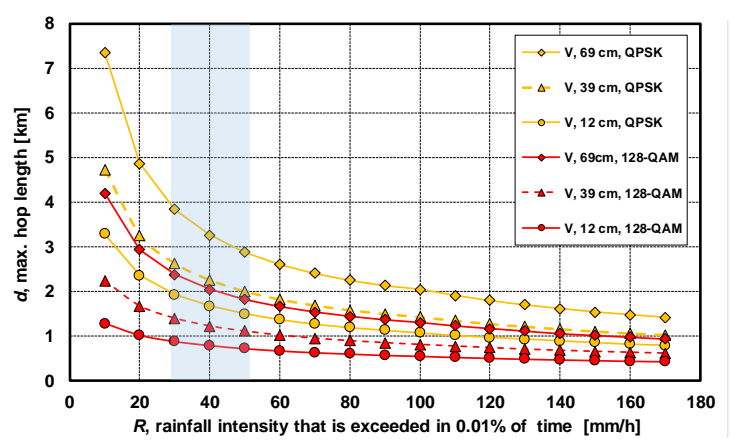

(e)

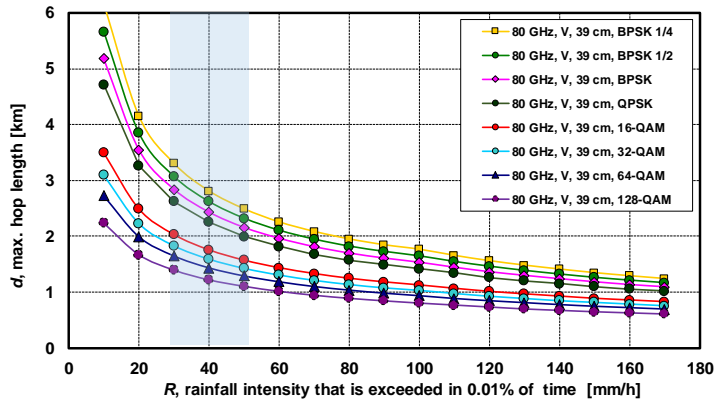

(b)

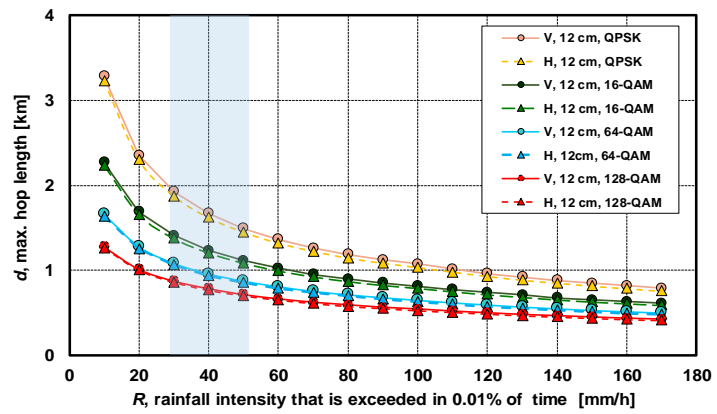

(d)

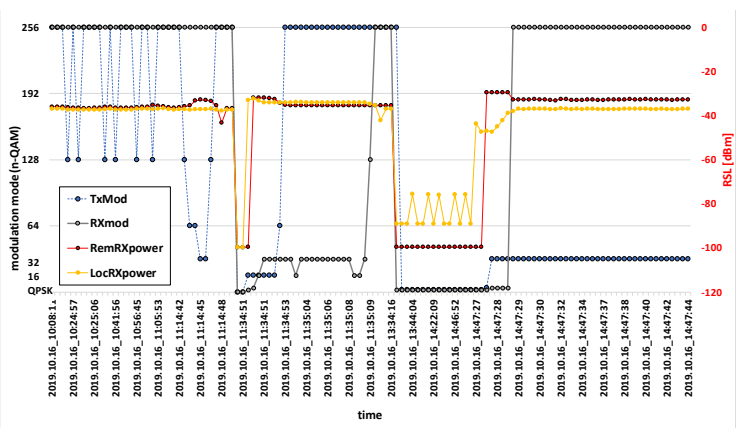

(f)

Figure 16. Recommended hop lengths as a function of rainfall intensity. (a) Hops with vertical polarization, $1 \mathrm{GHz}$ channel and $\varnothing 12 \mathrm{~cm}$ dishes. (b) Hops with vertical polarization, $1 \mathrm{GHz}$ channel and $ø 39 \mathrm{~cm}$ dishes. (c) Hops with vertical polarization, $1 \mathrm{GHz}$ channel and ø $69 \mathrm{~cm}$ dishes. (d) Comparison of vertical and horizontal links at the different modulation modes. (e) Comparison of hops with different dish sizes. Modulations are quadrature phase-shift keying (QPSK) and 128-QAM. (f) Example of monitoring the local and remote received signal level (RSL) and modulation modes.

\section{Local Rainfall Rates and Experimental Verification}

As seen in the global rain-rate map of Figure 17, the Central and Eastern European countries fall mainly into the rain-rate zones of $25 \mathrm{~mm} / \mathrm{h}, 32 \mathrm{~mm} / \mathrm{h}$, and $42 \mathrm{~mm} / \mathrm{h}$, called E, H, and K zones in the ITU recommendations. In the planning phase, the rainfall rate is often approximated with one single value for medium and small countries, i.e., $42 \mathrm{~mm} / \mathrm{h}$ for the entire territory of Hungary, following ITU-R P.837-1 [37]. 


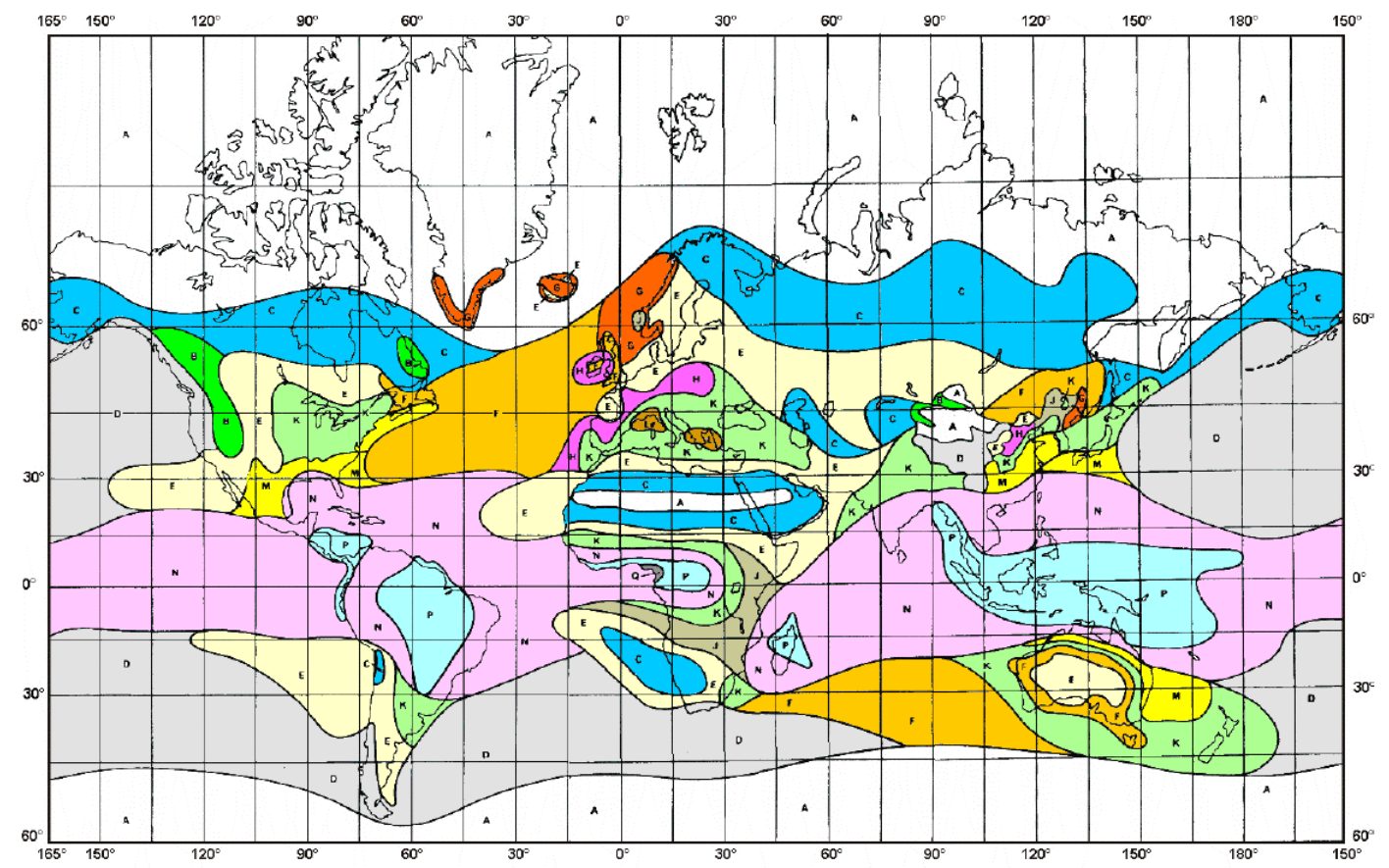

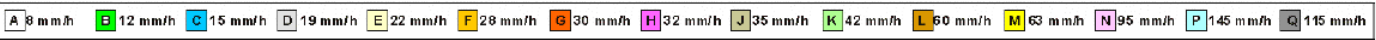

Figure 17. Global map of rain-rate zones, reproduced with permission from RACOM [51].

It is worth mentioning that advanced link planning tools provide the possibility to define rain-rate polygons inside a country when more accurate data are available. Even for medium- or relatively small-size European countries, the rainfall rate may change significantly inside the country. Switzerland is shown in Figure 18a as an example, where the $R_{0.01 \%}$ rain rates vary from $26 \mathrm{~mm} / \mathrm{h}$ to $46 \mathrm{~mm} / \mathrm{h}$ in the different rain zones. Research activities are ongoing in several countries to determine accurate local rainfall rates, specific for the region. Fixed $\mu / \mathrm{mmW}$ links are monitored together with meteorological data continuously. There are also remarkable long-term rain-rate measurement activities in the Czech Republic and in Hungary [12,44,52,53]. Rainfall and RSL results are stored with high accuracy and time resolution. The statistical evaluation of rain attenuation is based on the long-term data collected experimentally. Figure $18 \mathrm{~b}$ shows significant rainfall intensity differences calculated for Hungary [53]. Long-term trial and operator network experience were also published for the $58 \mathrm{GHz}$ and $73 \mathrm{GHz}$ links $[44,45,52,53]$.

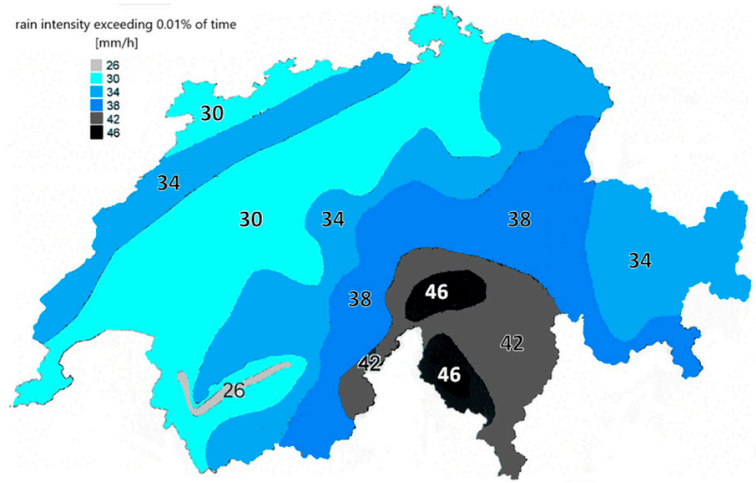

(a)

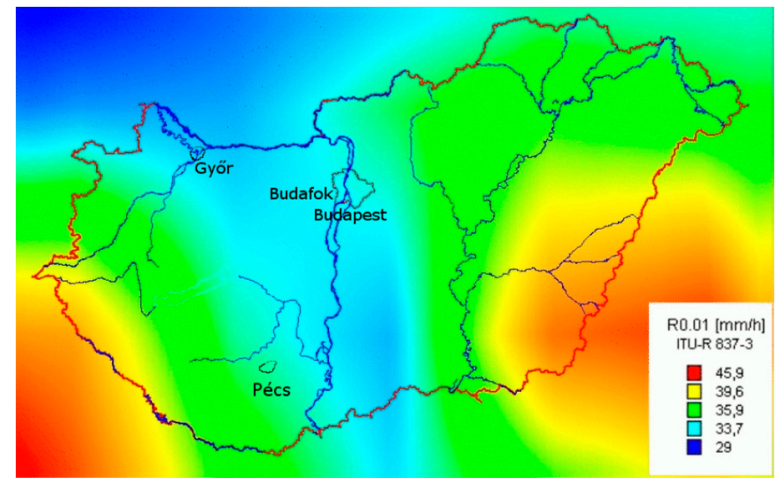

(b)

Figure 18. $R_{0.01 \%}$ in $\mathrm{mm} / \mathrm{h}$, the rainfall intensities exceeded $0.01 \%$ of the time. (a) Rain-rate contour lines in Switzerland. (b) Rain-rate regions in Hungary as calculated in Reference [53]. The figure is reproduced with permission from László Csurgai-Horváth. 
A very accurate meteorological report is available, e.g., for Norway [54]. Rainfall intensities exceeded for $0.5 \%, 0.1 \%, 0.01 \%$, and $0.001 \%$ of the time were measured over several decades. Such an accurate report is very helpful in the availability design of $\mu / \mathrm{mmW}$ links (Figure 19).

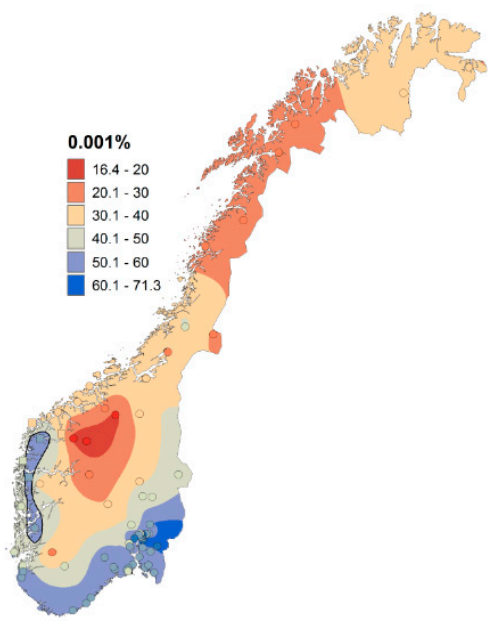

(a)

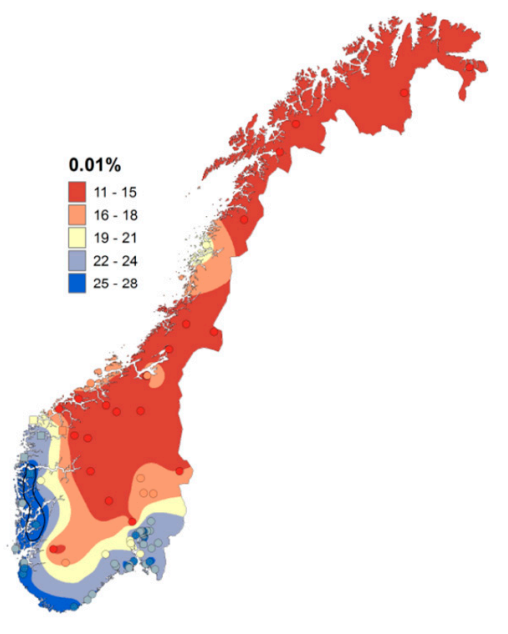

(b)

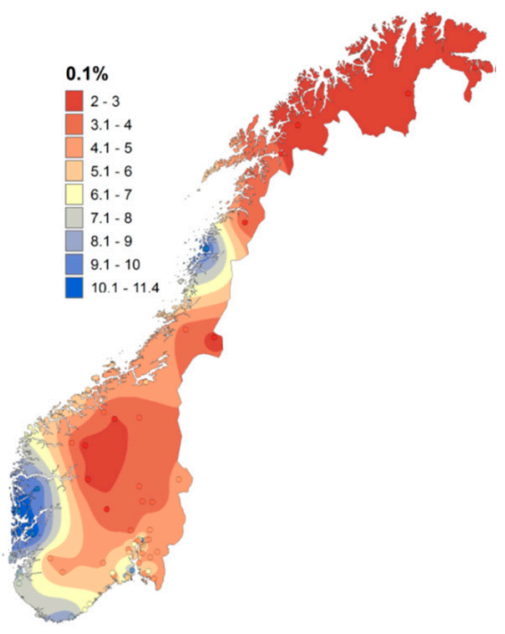

(c)

Figure 19. Rainfall maps of Norway measured over a long period. (a) Rainfall rates in $\mathrm{mm} / \mathrm{h}$, exceeded $0.001 \%$ of the time. (b) Rainfall rates in $\mathrm{mm} / \mathrm{h}$, exceeded $0.01 \%$ of the time. (c) Rainfall rates in $\mathrm{mm} / \mathrm{h}$, exceeded $0.1 \%$ of the time. Reproduced with permission from the Norwegian Meteorological Institute [54].

\section{Discussion}

Microwave and millimeter-wave links continue to support the mobile anyhaul networks both for the legacy and the new $5 \mathrm{G}$ radio access points. Site densification and new fiber-optical aggregation points result in shorter hop lengths for the $\mu / \mathrm{mmW}$ links. In the coming years, a mesh topology composed of fiber-optical, FSO, and $\mu / \mathrm{mmW}$ radio links will be used with load sharing and route diversity techniques. In the radio hops adaptive modulation, ATPC and channel aggregation techniques support higher bit rates. New millimeter-wave frequency bands will receive emphasis thanks to the wide spectrum available. In the millimetric $\mathrm{E}$ and $\mathrm{V}$ bands, multi-Gbps links can support 5G deployments with high bit rates and low latency.

In this paper, hop-length recommendations were given for the digital $\mu / \mathrm{mmW}$ radio links. Using the ITU recommendations for rain and atmospheric attenuation, a detailed fade margin and availability calculation method was presented. The presented calculation method takes antenna size, link frequency, polarization, and modulation mode into account. Example radio link calculations were shown with typical system gain and antenna size values. During the numerical calculations, rainfall rate statistics were considered that are typical in Central and Eastern European countries. Recommended hop length was plotted as a function of rainfall rate for the different frequency bands, link polarizations, and dish sizes. The calculated charts provide useful help in the planning, optimization and monitoring of $\mu / \mathrm{mmW}$ links.

Finally, it was shown with rain-rate maps that, even in medium- or small-size countries, there may be significant rainfall rate differences in Europe. For more accurate availability and optimal hop-length calculations, locally collected meteorological data should be utilized in the radio link planning tools. As a result, the new links can be planned with the required availability targets, and the existing access network can be optimized to support the increased capacity demands of $5 \mathrm{G}$ deployments.

Funding: This research received no external funding.

Acknowledgments: The author thanks his current and former colleagues for the fruitful discussions and for the valuable support: Gábor Járó, Szabolcs Sülle, Tina Hinch, and Radu Paducel (Nokia Software and Nokia Mobile 
Networks), László Csurgai-Horváth, Lajos Nagy, Éva Gödör, and Tibor Berceli (BME, the Budapest University of Technology and Economics), Julianna Györösi (HIF, the Hungarian Communications Authority and TKI, the Research Institute for Telecommunications), János Ladvánszky (TKI and Ericsson), and Viktor Fehérvári (T2-Com Ltd.). All personal communications and valuable comments given by Trevor Manning, TMC Global, Australia and Lajos Hanzó, Southampton University, UK are highly appreciated. The author acknowledges ETSI, ITU, MetNo and RACOM for providing approvals and for their quick support.

Conflicts of Interest: The authors declare no conflicts of interest.

\section{Acronyms}

\begin{tabular}{|c|c|}
\hline A & availability \\
\hline $\mathrm{A}_{\mathrm{a}}$ & atmospheric attenuation \\
\hline $\mathrm{A}_{\mathrm{o}}$ & obstacle loss \\
\hline$A_{\mathrm{sp}}$ & specific attenuation (in $\mathrm{dB} / \mathrm{km}$ ) \\
\hline ATPC & automatic transmit power control \\
\hline BER & bit error rate \\
\hline BPSK & binary phase-shift keying \\
\hline CEPT & The European Conference of Postal and Telecommunications Administrations \\
\hline d & distance: hop length of the radio links \\
\hline $\mathrm{dB}$ & deciBel \\
\hline $\mathrm{dBi}$ & antenna gain in $\mathrm{dB}$ unit, compared to the gain of the isotropic antenna \\
\hline $\mathrm{dBm}$ & power in $\mathrm{dB}$, relative to $1 \mathrm{~mW}$ \\
\hline EN & European Norm \\
\hline ETSI & European Telecommunication Standards Institute \\
\hline FEC & forward error correction \\
\hline FM & fade margin \\
\hline FSL & free space loss \\
\hline FSO & free space optical (link) \\
\hline $\mathrm{G}_{\text {ant }}$ & antenna gain \\
\hline $\mathrm{G}_{\mathrm{RXa}}$ & antenna gain of the receiver \\
\hline $\mathrm{G}_{\mathrm{TXa}}$ & antenna gain of the transmitter \\
\hline Gbps & gigabit/second \\
\hline $\mathrm{H}$ & horizontal (polarization of a link) \\
\hline HSPA & high speed packet access \\
\hline IDU & indoor unit \\
\hline ITU & International Telecommunication Union \\
\hline LoS & line-of-sight \\
\hline LTE & long-term evolution \\
\hline LTE-A & LTE Advanced \\
\hline Mbps & megabit/second \\
\hline $\mathrm{mmW}$ & millimeter-wave frequencies: $30 \mathrm{GHz}-300 \mathrm{GHz}$ \\
\hline NW & network \\
\hline ODU & outdoor unit \\
\hline PL & propagation loss \\
\hline$P_{R X}$ & power received at the input of the transceiver \\
\hline $\mathrm{P}_{\mathrm{TX}}$ & power transmitted at the output of the transceiver \\
\hline$P_{\text {RXth }}$ & receiver threshold (for BER $=10^{-6}$ ) \\
\hline$P_{R X u}$ & unfaded RSL at the input of the transceiver \\
\hline PoP & point of presence \\
\hline QAM & quadrature amplitude modulation \\
\hline QPSK & quadrature phase-shift keying \\
\hline $\mathrm{R}$ & rainfall rate in $\mathrm{mm} / \mathrm{h}$ \\
\hline RAN & radio access network \\
\hline
\end{tabular}




$\begin{array}{ll}\text { RAP } & \text { radio access point } \\ \text { RAT } & \text { radio access technology } \\ \text { RF } & \text { radio frequency } \\ \text { RoF } & \text { radio-over-fiber } \\ \text { RSL } & \text { received signal level } \\ \text { RX } & \text { receive or receiver } \\ \text { SG } & \text { system gain } \\ \text { SGa } & \text { system gain with TX and RX antenna gains included } \\ \text { TCM } & \text { trellis coded modulation } \\ \text { TX } & \text { transmit or transmitter } \\ \text { U } & \text { unavailability } \\ \text { V } & \text { vertical (polarization of a link) } \\ \varnothing & \text { diameter } \\ \mu / \mathrm{mmW} & \text { microwave and millimeter-wave } \\ 2 \mathrm{G} & \text { 2nd generation mobile network, GSM } \\ 3 \mathrm{G} & \text { 3rd generation mobile network, UTRAN } \\ 4 \mathrm{G} & \text { 4th generation mobile network, LTE } \\ 5 \mathrm{G} & \text { 5th generation mobile network }\end{array}$

\section{References}

1. Hilt, A. Microwave hop-length and availability targets for the $5 \mathrm{G}$ mobile backhaul. In Proceedings of the 42nd Telecommunications and Signal Processing Conference (TSP'2019), Budapest, Hungary, 1-3 July 2019; pp. 1-8.

2. Varga, J.; Hilt, A.; Rotter, C.; Járó, G. Providing ultra-reliable low latency services for 5G with unattended datacenters. In Proceedings of the 11th International Symposium on Communication Systems, Networks \& Digital Signal Processing (CSNDSP'2018), Budapest, Hungary, 18-20 July 2018; pp. 1-5.

3. GSMA. Road to 5G Introduction and Migration. In White Paper; GSM Association: London, UK, April 2018. Available online: https://www.gsma.com/futurenetworks/wp-content/uploads/2018/04/Road-to-5GIntroduction-and-Migration_FINAL.pdf (accessed on 17 October 2019).

4. GSMA. Mobile Backhaul Options, Spectrum Analysis and Recommendations. In White Paper; GSM Association: London, UK, September 2018. Available online: https://www.gsma.com/spectrum/resources/ mobile-backhaul-options/ (accessed on 17 October 2019).

5. Batagelj, B.; Capmany, J.; Udvary, E. 5th-generation mobile access networks assisted by integrated microwave photonics. In Proceedings of the International Workshop on Fiber Optics in Access Networks (FOAN'2019), Sarajevo, Bosnia Hercegovina, 1-4 September 2019.

6. Lombardi, R. Microwave and millimetre-wave for 5G transport. In White Paper, 1st ed.; ETSI: Sophia Antipolis, France, 2018.

7. Metsälä, E.M.; Salmelin, J.T.T. (Eds.) LTE Backhaul Planning and Optimization, 1st ed.; John Wiley \& Sons Ltd.: Chichester, UK, 2016.

8. Hilt, A.; Pozsonyi, L. Application of fiber-optic techniques in the transport and access transmission networks of mobile systems. In Proceedings of the Fiber Optics in Access Networks (FOAN-ICUMT'2011), Budapest, Hungary, 5-7 October 2011.

9. Nokia. The evolution of microwave transport- enabling 5G and beyond. In White Paper; Nokia: Espoo, Finland, 2019.

10. Hanzó, L.; Ng, S.X.; Keller, T.; Webb, W.T. Quadrature Amplitude Modulation: From Basics to Adaptive Trellis-Coded, Turbo-Equalised and Space-Time Coded OFDM, CDMA and MC-CDMA Systems, 1st ed.; John Wiley \& Sons Inc.: New York, NY, USA, 2004.

11. Li, H.; Zhang, J.; Hong, Q.; Zheng, H.; Zhang, J. Exploiting adaptive modulation in E-band software-defined backhaul network. In Proceedings of the 8th Annual Computing and Communication Workshop and Conference (CCWC'2018), Las Vegas, CA, USA, 8-10 January 2018; pp. 1009-1013.

12. Coldrey, M. (Ed.) Maturity and field proven experience of millimetre wave transmission. In White Paper, 1st ed.; ETSI: Sophia Antipolis, France, 2015.

13. Nokia. Mobile anyhaul. In White Paper; Nokia: Espoo, Finland, 2017. 
14. Nokia. Boosting capacity: Why you need 10G interfaces on microwave radios, the value of Nokia 9500 MPR. In Application Note; Nokia: Espoo, Finland, 2017.

15. Hilt, A.; Berzéthy, P. Recent trends in reliable access networking for GSM systems. In Proceedings of the Conference on Design of Reliable Communication Networks (DRCN'2001), Budapest, Hungary, 7-10 October 2001; pp. 91-98.

16. Frigyes, I.; Csurgai-Horváth, L. Free-space optics and E-band radio: Complementary techniques for Gbit/sec wireless. In Proceedings of the Wireless Communications and Networking Conference Workshops (WCNCW'2010), Sidney, Australia, 18 April 2010.

17. Liu, C.; Wang, J.; Cheng, L.; Zhu, M.; Chang, G.-K. Key microwave-photonics technologies for next-generation cloud-based radio access networks. J. Lightwave Technol. 2014, 32, 3452-3460. [CrossRef]

18. Hilt, A.; Udvary, E.; Járó, G.; Berceli, T. Harmonic components and dispersion of mobile network signals due to fiber-optical transmission. In Proceedings of the Conference on Optical Network Design and Modelling (ONDM'2017), Budapest, Hungary, 15-18 May 2017.

19. Batagelj, B.; Pavlovič, L.; Naglič, L.; Tomažič, S. Convergence of fixed and mobile networks by radio over fibre technology. Inf. Midem-Ljubl. 2011, 41, 144-149.

20. Sung, J.-Y.; Chow, C.-W.; Yeh, C.-H.; Chang, G.-K. Two-level modulation scheme to reduce latency for optical mobile fronthaul networks. Opt. Express 2016, 24, 25767-25773. [CrossRef] [PubMed]

21. Varga, J.; Hilt, A.; Bíró, J.; Rotter, C.; Járó, J. Reducing operational costs of ultra-reliable low latency services in 5G. HTE Infocommun. J. 2018, 4, 37-45.

22. Giorgi, L.; Bruno, G.; Nijhof, J.; Urban, P.J.; Vall-llosera, G.; Ponzini, F.; Ladvánszky, J. Subcarrier multiplexing RF plans for analog radio over fiber in heterogeneous networks. J. Lightwave Technol. 2016, 34, 3859-3866. [CrossRef]

23. llgaz, M.A.; Batagelj, B. Proposal for distribution of a low-phase-noise oscillator signal in forthcoming fifth-generation mobile network by radio-over-fibre technology. In Proceedings of the 58th International Symposium Electronics in Marine (ELMAR'2016), Zadar, Croatia, 12-14 September 2016; pp. 13-16.

24. Draft ETSI EN 302 217-1 V3.2.0. Fixed Radio Systems; Characteristics and Requirements for Point-to-Point Equipment and Antennas; Part 1: Overview, Common Characteristics and System-Dependent Requirements; ETSI: Sophia Antipolis, France, 2019.

25. ETSI GR mWT 012 V1.1.1. 5G Wireless Backhaul/X-Haul; ETSI: Sophia Antipolis, France, 2018.

26. Sellin, G. (Ed.) Ericsson Microwave Outlook; Ericsson: Göteborg, Sweden, 2018.

27. CEPT ECC Rec. (05)07. Radio Frequency Channel Arrangements for Fixed Service Systems Operating in the Bands 71-76 GHz and 81-86 GHz. CEPT, 2009, 2013. Available online: https://www.ecodocdb.dk/download/ 9c4f8690-d0e1/REC0507.PDF (accessed on 18 October 2019).

28. CEPT ECC Rec. (18)02. Radio Frequency Channel/Block Arrangements for Fixed Service Systems Operating in the Bands 92-94 GHz, 94.1-100 GHz, 102-109.5 GHz and 111.8-114.25 GHz; CEPT, September 2018. Available online: https://www.ecodocdb.dk/download/476602d1-6145/ECCRec1802.pdf (accessed on 18 October 2019).

29. CEPT ECC Rec. 18(01). Radio Frequency Channel/Block Arrangements for Fixed Service Systems Operating in the Bands 130-134 GHz, 141-148.5 GHz, 151.5-164 GHz and 167-174.8 GHz; CEPT, April 2018. Available online: https://www.ecodocdb.dk/download/a5533f97-5a92/Rec1801.pdf (accessed on 18 October 2019).

30. Mohammad, A.W.M. Integrated Photonics for Millimetre Wave Transmitters and Receivers. Ph.D. Thesis, University College London, London, UK, February 2019.

31. Manning, T. Microwave Radio Transmission Design Guide, 2nd ed.; Artech House: London, UK, 2009.

32. Manning, T. Microwave Radio Handy Reference Guide, 1st ed.; TMC Global: Brisbane, Australia, 2019.

33. Hansryd, J.; Edstam, J. Microwave capacity evolution. Ericsson Rev. 2011, 1, 22-27.

34. RACOM Radio Data Networks. Dual RAy \& OMT. Application Note, October 2018. Available online: https://www.racom.eu/eng/products/m/ray/app/omt/index.html (accessed on 23 October 2019).

35. 100 Gbps Over Microwave Link. Available online: https://www.telekom.com/en/media/media-information/ archive/milestone-for-5g-technology-572112 (accessed on 18 October 2019).

36. Rec. ITU-R P.530-(5)-17. Propagation data and prediction methods required for the design of terrestrial line-of-sight systems. In P Series, Radiowave Propagation; International Telecommunication Union: Geneva, Switzerland, (1978)-2017.

37. Rec. ITU-R P.837-(1)-7. Characteristics of precipitation for propagation modelling. In P Series, Radiowave Propagation; International Telecommunication Union: Geneva, Switzerland, (1992)-2017. 
38. Rec. ITU-R P.838-(0)-3. Specific attenuation model for rain for use in prediction methods. In $P$ Series, Radiowave Propagation; International Telecommunication Union: Geneva, Switzerland, (1992)-2005.

39. Rec. ITU-R P.676-(3)-12. Attenuation by atmospheric gases and related effects. In P Series, Radiowave Propagation; International Telecommunication Union: Geneva, Switzerland, (1990)-2019.

40. ITU Radiocommunication Bureau. Handbook, Digital Radio-Relay Systems; International Telecommunication Union: Geneva, Switzerland, 1996.

41. Tomasi, W. Advanced Electronic Communications Systems, 6th ed.; Pearson New International Edition: Essex, UK, 2014.

42. Hilt, A.; Forgó, L.; Tatár, S.; Tóth, I. Spectral stability of radio transmitters in point-to-multipoint access systems. In Proceedings of the 10th Microwave Colloquium (MICROCOLL'1999), Budapest, Hungary, 21-24 March 1999; pp. 231-234.

43. Hilt, A.; Pap, T. Fixed MW access network design using interference matrices. In Proceedings of the 11th Microwave Colloquium (MICROCOLL'2003), Budapest, Hungary, 10-11 September 2003; pp. 169-172.

44. Kvičera, V.; Grabner, M. Rain attenuation at 58 GHz: Prediction versus long-term trial results. EURASIP J. Wirel. Commun. Netw. 2007, 1-7. [CrossRef]

45. Hilt, A.; Pap, T. Application of $58 \mathrm{GHz}$ band for GSM access networks in Hungary. In Proceedings of the 11th Microwave Colloquium (MICROCOLL'2003), Budapest, Hungary, 10-11 September 2003; pp. 81-84.

46. Räisänen, A.V.; Sehm, T.; Lehto, A.; Laurinaho, J.A. Low-profile solutions for high-gain antennas and their measurements at millimeter wavelengths. In Proceedings of the 13th International Conference on Microwaves, Radar and Wireless Communications (MIKON'2000), Wroclaw, Poland, 22-24 May 2000; Volume 3, pp. 183-188.

47. Andrew Corporation. ValuLine ${ }^{\circledR}$ III Next generation antennas. VHLP1. In Product Specification; CommScope: Hickory, NC, USA, 2007.

48. Andrew Corporation. ValuLine ${ }^{\circledR}$ III Next generation antennas. VHLP2. In Product Specification; CommScope: Hickory, NC, USA, 2007.

49. Hilt, A.; Petrás, P.; Emsley, D.; Rybarczyk, G. Access transmission network upgrade in a nationwide mobile network modernization project for EDGE deployment. In Proceedings of the 13th International Telecommunications Network Strategy and Planning Symposium, (Networks'2008), Budapest, Hungary, 28 September-2 October 2008; pp. 1-10.

50. Hilt, A.; Petrás, P. Microwave transmission node optimization for access capacity increase in mobile networks. In Proceedings of the Microwave Optical Week (MICROCOLL'2007), Budapest, Hungary, 14-16 May 2007; pp. 109-112.

51. RACOM Radio Data Networks. RAy Link Calculation. Application Note, December 2018. Available online: https://www.racom.eu/eng/products/m/ray/app/linkcalc/index.html (accessed on 23 October 2019).

52. Csurgai-Horváth, L.; Frigyes, I. E-band terrestrial radio-propagation and availability aspects. HTE Infocommun. J. 2015, 1, 28-33.

53. Csurgai-Horváth, L. Digital Modelling of Fade and Interfade Duration on High Frequency Radio Links and its Application in Time Series Synthesis. Ph.D. Thesis, BME, Budapest University of Technology and Economics, Budapest, Hungary, 2010.

54. Mamen, J.; Benestad, R.; Haugen, J.E. Analysis of Short Term Precipitation in Norway 1967-2010; Norwegian Meteorological Institute: Oslo, Norway, 2011.

(C) 2019 by the author. Licensee MDPI, Basel, Switzerland. This article is an open access article distributed under the terms and conditions of the Creative Commons Attribution (CC BY) license (http://creativecommons.org/licenses/by/4.0/). 